A 11703 4l7418

PUBLICATIONS

NIST BUILDING SCIENCE SERIES 169

\title{
Strength and Creep-Rupture Properties of Adhesive-Bonded EPDM Joints Stressed in Peel
}

Jonathan W. Martin

Edward Embree

Paul E. Stutzman

James A. Lechner

TA

435

.058

\#169

1990

C. 2 


\section{NATIONAL INSTITUTE OF STANDARDS \& TECHNOLOGY Research Information Center Gaithersburg, MD 20899}

\section{DATE DUE}

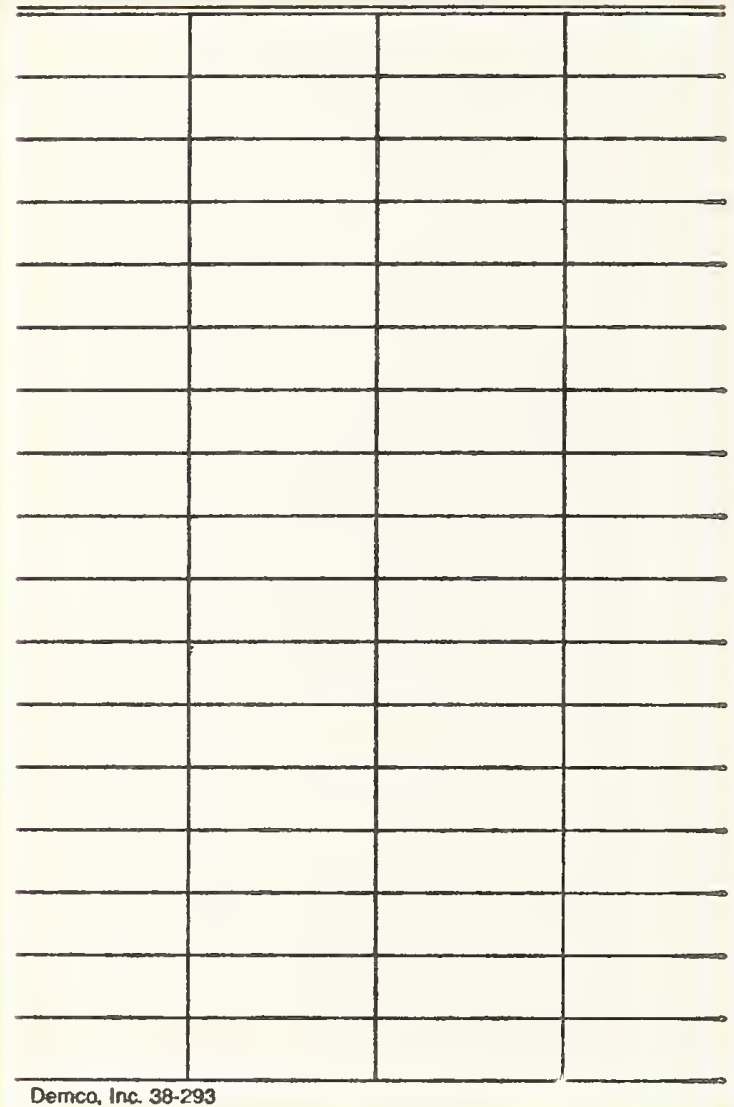




\section{NIST BUILDING SCIENCE SERIES 169}

\section{Strength and Creep-Rupture Properties of Adhesive-Bonded EPDM Joints Stressed in Peel}

Jonathan W. Martin

Edward Embree

Paul E. Stutzman

James A. Lechner

National Engineering Laboratory

National Institute of Standards and Technology

Gaithersburg, MD 20899

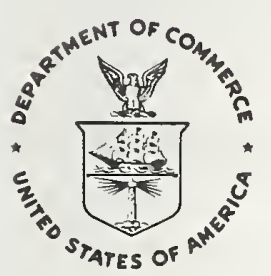

Issued May 1990

U.S. DEPARTMENT OF COMMERCE, Robert A. Mosbacher, Secretary NATIONAL INSTITUTE OF STANDARDS AND TECHNOLOGY John W. Lyons, Director 
National Institute of Standards and Technology Building Science Series 169 Natl. Inst. Stand. Technol. Bldg. Sci. Ser. 169, 59 pages (May 1990)

CODEN: NBSSES

\section{U.S. GOVERNMENT PRINTING OFFICE}

WASHINGTON: 1990

For sale by the Superintendent of Documents, U.S. Government Printing Office, Washington, DC 20402-9325 


\section{ABSTRACT}

The most frequently reported defect in ethylene-propylenediene terpolymer (EPDM) single-ply roofing systems is in fieldformed joints. The causes of these joint defects are largely unknown, but they tend to occur a short time after a roof is installed.

The objectives of this research were 1) to determine the importance of the following material and fabrication variables in causing joint failures: adhesive thickness, cure time, mechanical load, adhesive type and surface cleanness, 2) to rank these variables as they affect the creep-rupture life and strength of butyl-adhered EPDM joints, and 3) to determine the maximum peel stress which EPDM joints can sustain over their design life.

From our results, cure time and level of cleanness of the EPDM membrane have the greatest effect on joint strength; while the thickness of the adhesive and the magnitude of the mechanical load have the greatest effect on a joint's creep-rupture time-tofailure. Thus, the rankings of variables in creep-rupture and short-time strength experiments were different and this difference should have important implications in standards writing and in establishing performance requirements for EPDM roofing joints.

Creep-rupture results were used in determining the maximum design stress that butyl and neoprene-adhered EPDM joints can sustain when loaded in peel. The maximum sustainable stress is only a small fraction (less than 5\%) of the short-time y eld strength of a joint. Thus, efforts should be made to insure the the field-formed joints are only subjected to small peel loads.

KEYWORDS: butyl adhesive; creep-rupture life; EPDM; neoprene; peel performance criteria; seam; single-ply roofing; strain rate; stress-ratio; time-to-failure 
$-$ 
Abstract

1. Introduction

2. Background.

2.1 Stress Distribution Along the Peel Line.

2.2 Peel Force.

2.3 Rate of Peel

3. Peel Force of Butyl-Adhered EPDM Joints. . . . . . . . .6

3.1 Experimental . . . . . . • . . . . . . . 6

3.1.1 Materials . . . . . . . . . . . . . 6

3.1.2 Specimen contamination. . . . . . . . . . 7

3.1.3 Contamination Level Quantification. . . . . 8

3.1.4 Specimen Preparation and Test Procedure. . 8

3.2 Model of Strength Versus Cure Time . . . . . . . . 10

3.3 Results . . . . . . . . . . . . . . . . 11

3.3.1 Failure Modes . . . . . . . . . . . 12

3.3.2 Effect of Adhesive Thickness on Peel. . . . 12

3.3.3 Strength Versus Cure Time at Different. . . 13

Contamination Levels

3.4 Discussion . . . . . . . . . . . . . . . 16

3.5 Peel Strength Conclusions. . . . . . . . . . . 17

4. Creep-Rupture Times-to-Failure of Butyl-Adhered EPDM . . 17 Joints

4.1 Experimental • . . . . . . . . . . . . . . . 18

4.1.1 Materials . . . . . . . . . . . . 18

4.1.2 Experimental Procedure. . . . . . . . . 18

4.2 Results . . . . . . . . . . . . . . . . . . 19

4.2.1 Peel Strength at Long Cure Times. . . . . 19

4.2.2 Failure Mode . . . . . . . . . . . . 20

4.2.3 Creep-Rupture Times-to-Failure. . . . . . 22

4.3 Discussion . . . . . . . . . . . . . . . . . 25

4.4 Creep-Rupture Time-to-Failure Conclusions. . . . . 25

5. Comparison of Times-to-Failure for Butyl- and . . . . . 26 Neoprene-Adhered EPDM Joints as a Function of Load Ratio

6. Summary. . . . . . . . . . . . . . . . 28

7. Acknowledgments. . . . . . . . . . . . . . . . . 29

8. References . . . . . . . . . . . . . . . . . 30

9. List of Symbols. . . . . . . . . . . . . . . . . 34 

EPDM (ethylene-propylene-diene terpolymer) single-ply roofing membranes are widely used in the United states for lowsloped roof applications. The popularity of this system stems in part from the chemical inertness of EPDM, which provides the membrane with its excellent weathering properties. This inertness also makes it difficult to achieve the strong adhesive bond between two EPDM sheets which is needed to assure the quality of a field-formed seam. Evidence for this difficulty is available from Project Pinpoint's data (Cullen, 1984, 1988, 1989), from case studies conducted by NIST staff (Rossiter and Seiler 1988, 1989), and from general survey papers on the performance of single-ply roofing systems (Dupuis, 1983; Dregger, 1988; Russo 1988).

The adhesives most commonly used in fabricating field-formed EPDM seams are neoprene and butyl adhesives. Prior to 1986, the neoprene adhesives were dominant, but since that time, the neoprene adhesives have been largely supplanted by the butyl adhesives. This switch resulted from improvements in the formulation of butyl adhesives and from problems with the durability of neoprene adhesives. The change in adhesives has not, however, produced any noticeable improvements in Project Pinpoint's seam defect statistics, which have remained relatively constant, at approximately $25 \%$ of the defects reported for single-ply roofing membranes.

Since no significant change has occurred in the defect statistics for seams of single-ply membranes, it seems reasonable to conclude that the causes of these defects have not, as yet, been identified. The source of these defects, however, can be garnered from Project Pinpoint's 1984 survey. In that survey (Cullen, 1984), it was reported that $62 \%$ of all reported seam defects occur within the first year, $74 \%$ within the first 2 years, and $86 \%$ within the first 3 years after installation. Thus, we can conclude that most seam defects occur within a short time after a roof is installed, implicating weaknesses in the materials, the design, or the fabrication of a seam, as opposed to the chemical or physical aging of one or more of the seam components. The presumption that seam defects are not caused by the chemical degradation of the seam components is further supported by the chemical inertness of butyl adhesives (Stucker, 1977 ) and EPDM rubber, and by the observation that switching from neoprene to butyl adhesives did not affect Project Pinpoint's seam defect statistics.

The fabrication of a quality field-formed seam depends on many material, environmental, and application factors, including the shelf life of the adhesive, the thickness of the adhesive, the membrane cleaning procedure, and the membrane temperature and 
wetness. The effect of each of these factors should be known to assure the fabrication of a quality field-formed seam. These interactions can be unraveled through the application of welldesigned multivariate experiments (Box et al., 1978).

The objectives of this study were to determine the relative importance of several fabrication variables (adhesive thickness, cure time, level of surface contamination of the EPDM sheet, mechanical load, and adhesive type) on the short-time strength (sec. 3) and creep-rupture lives (sec. 4) of butyl-adhered EPDM joints. These results were then compared with previously published results for neoprene-adhered EPDM joints (sec. 5). only four factors were varied in each experiment, two of which (adhesive thickness and level of surface contamination) were common to both the short-time strength and creep-rupture experiments. This redundancy was built into the experimental design to determine if the rankings of these factors remained the same when the strain rate was varied.

\section{BACKGROUND}

The seams in this study were stressed in peel, as opposed to lap-shear (see discussion in Rossiter, 1987). Failure in peel is implicated as the cause of many different types of seam defects, some of which are shown in figure 1. Peel tests are also easier to interpret on a scientific basis, are more sensitive to small changes in the magnitude of different application variables (Rossiter, 1988), require lower stresses (Rossiter, 1987), and have shorter creep-rupture lives than do similarly fabricated joints under comparable lap-shear loads.

The factors to be included in the experimental design were selected based on a review of the literature and on extensive conversations with EPDM membrane manufacturers, roofing contractor representatives, and consultants. From these sources, the removal of contaminants from the membrane prior to the application of the adhesive was consistently identified as the single most important factor for insuring the quality of a fieldformed seam. The contaminants of interest are the talc-like particulates (talc, clay, or mica; hereinafter termed contaminants) which are commonly applied over the surface of most commercial EPDM membranes to prevent interply fusion during vulcanization. These contaminants also act to deter interply sticking during the storage and shipment of the cured rubber (Wake 1969; Westley 1982) and to facilitate the movement of the rubber sheets during roof construction. These positive attributes are somewhat counterbalanced, however, by the negative impact that they have on the formation of a strong adhesive bond (Wake 1969; Rossiter 1988; Martin, Embree 1989).

In the following subsections, factors affecting the mechanics of peel are reviewed. This review emphasizes systems 
similar to those investigated in our experiments, namely, uncrosslinked, elastomeric adhesives, having thicknesses less than their critical adhesive thickness, which are stressed at a low peel rate and at a temperature far above the glass transition temperatures of both the adhesive and EPDM.

\subsection{Stress Distribution Along the Peel Line}

Equations for cleavage stress and peel force have been developed from small beam theory by Kaelble (1965). In deriving these equations, the adhesive and adherend were assumed to be linear elastic and the stresses developed across the width and the thickness of the specimen were assumed to be uniform and constant. The resulting equations for cleavage stress, $\sigma_{c}$, at a distance, $-x$ (see fig. 2), from the peel front (where $x=0$ ) are given by

$$
\sigma_{c}=\sigma_{o}\left(\cos \delta x+k_{\theta} \sin \delta x\right) \exp (\delta x)
$$

where

$$
\begin{aligned}
& \delta \quad=\left(\mathrm{E}_{\text {adh }} \mathrm{W} / 4 \mathrm{EIT}_{\mathrm{adh}}\right)^{1 / 4} \\
& \mathrm{~K}_{\theta}=\delta \mathrm{m} /(\delta \mathrm{m}+\sin \Theta) \\
& \sigma_{0}=\text { boundary stress at } \mathrm{x}=0 \\
& \mathrm{E}_{\text {adh }}=\text { tensile modulus of elasticity of the adhesive } \\
& \mathrm{W}=\text { tensile modulus of elasticity of the adherend } \\
& \mathrm{W}=\text { joint width } \\
& \mathrm{I}=\text { moment of inertia } \\
& \mathrm{m}=\text { moment arm } \\
& \Theta \quad=\text { peel angle } \\
& \mathrm{T}_{\text {adh }}=\text { adhesive thickness. }
\end{aligned}
$$

Equation 1 predicts that the cleavage stress is a highly damped harmonic function consisting of alternating zones of tension and compression. Equation 1 assumes that the joint does not carry any stresses behind the peel front; that is, for values of $x \geq 0$ (see fig. 2). This latter prediction is contrary to experimental observations, since joints stressed in peel often form filaments between the separating peel strips. These filaments are known to carry substantial tensile stress (Kaelble, 1965; Niesilowski, Aubrey 1981), as can be seen by comparing the theoretical and actual experimental stress distributions in figure 2 .

\subsection{Peel Force}

The peel force, $P$, can be derived from the work equation of peel (Kaelble, 1960, 1971) and is given by 


$$
\mathrm{P}=\mathrm{WT}_{\mathrm{adh}} \mathrm{K}_{\theta}^{2} \sigma_{0}^{2} /\left(2 \mathrm{E}_{\mathrm{adh}}(1-\cos \Theta)\right) \text {. }
$$

As is the case in our experiment, $K_{\theta}=1.0$ when $\Theta=90^{\circ}$, which simplifies eq (4) to

$$
\mathrm{P}=\mathrm{WT}_{\mathrm{adh}} \sigma_{0}^{2} / 2 \mathrm{E}_{\mathrm{adh}} \text {. }
$$

From eq (5), it can be seen that peel force per unit width is equal to the strain energy per unit area, $\mathrm{T}_{\text {adh }} \sigma_{0}^{2} / 4 \mathrm{E}_{\text {adh }}$, which in turn is proportional to adhesive thickness $\mathrm{T}_{\text {adh }}$.

Gent and Hamed (1977, 1978, 1982) have derived an alternative peel force equation based on the energy balance of cetachment during steady-state peel. From their analysis they concluded that the dependence of peel force on adhesive thickness results from energy dissipation losses within the bulk adhesive. The magnitude of these dissipation losses and, hence, the magnitude of the peel force, increases linearly with adhesive thickness up to a critical thickness; beyond which, the peel force remains constant. The existence of a critical thickness implies that energy can only be dissipated within a finite radial distance from the peel line, beyond which energy dissipation losses are not transmitted.

Gent and Petrich (1969) have earlier shown that these dissipation losses account for virtually all of the energy required to fail a joint. They deduced from their analysis that the tensile strain energy of the adhesive provides an independent approximation of peel strength. (Hereinafter, this approximation will be referred to as Gent and Petrich's approximation model.) Graphically, the tensile strain energy is given by the area under the stress/strain curve up to the point of maximum elongation; mathematically, it is computed from

$$
\mathrm{P} / \mathrm{W}=\mathrm{T}_{\mathrm{adh}} \int_{0}^{\sigma_{\max }} \mathrm{d} \mathrm{d} \epsilon
$$

where $\sigma_{\max }$ is the maximum tensile stress and $\epsilon$ is the tensile strain of the adhesive.

\subsection{Rate of Peel}

Strain rate and temperature have long been known to have equivalent effects on the viscoelastic response of a polymer. These effects can be modeled via the Williams, Landell, and Ferry (WLF) superposition principle, from which data collected at different strain rates and temperatures can be reduced to a single master curve by multiplying the data by a suitable shift factor (see for example Ferry, 1961). When the WLF-superposition principle was first discovered, it was verified against 
homogeneous materials. Later Bright (1954) and Kaelble (1964) applied the WLF-superposition principle to composite systems when they established that the shift factors for cohesive and interfacial joint failures were almost identical.

A typical peel force versus peel rate diagram (Gent and Petrich 1969) is presented in figure 3. At low peel rates, the macromolecules have time to disentangle and slip past one another (that is, the adhesive displays liquid-like flow behavior), resulting in a small peel force. As the peel rate increases, however, the internal friction within the polymer increases, since the macromolecules no longer have time to disentangle, resulting in an increase in peel force. This increase continues up to a critical peel rate, at which time an abrupt and precipitous drop in the peel force occurs (see fig. 3) and, with this drop, the failure mode changes from cohesive to interfacial. This critical peel rate has been interpreted by Gent and Petrich as a transition from liquid-like to rubber-like macromolecular behavior. As the peel rate increases from the liquid-like to rubber-like transition, the peel force again begins to increase until the peel rate reaches another critical value, at which time the peel force again drops. Gent and Petrich have interpreted this second critical peel rate as a transition from rubber-like to glass-like macromolecular behavior and attributed the loss in peel strength to the decreased flexibility of the solid adhesive. In the present experiment, however, the second transition is of little interest, since the peel rates associated with the rubberlike to glass-like transition are much higher than a roof seam would ever experience in service.

Gent and Petrich explained the complicated shape of the peel rate versus peel force diagram (fig. 4) using their approximation model. They assumed that the interfacial bond strength of a joint remains constant (the horizontal dashed line in fig. 4), regardless of the peel rate or temperature (a reasonable assumption according to Gent and Hamed (1978)). The observed peel force, therefore, depends only on the strain rate of the adhesive.

In figure 4, stress-strain curves are shown for an adhesive stressed at three different strain rates. Failure of a joint occurs whenever the maximum stress in the peel joint exceeds either the tensile strength of the adhesive (in which case, failure is by cohesion) or the interfacial bond strength (in which case, failure is interfacial). From eq (6), peel force is the area under the stress strain curve up to 1) the point of maximum extension of the adhesive, in the case of cohesive failure (e.g., $\epsilon_{\max 1}$ and $\epsilon_{\max 2}$ in fig. 4) or 2) the point that the tensile strength of the adhesive exceeds the interfacial bond strength of the adhesive to the substrate, in the case of interfacial failure (e.g., $\varepsilon_{\max 3}$ in fig. 4). Curves I and II correspond to an adhesive exhibiting liquid-like behavior, while 
Curve III corresponds to an adhesive exhibiting rubber-like elastic behavior. At the lowest peel rate (Curve I), the tensile strength of the adhesive is much less than the interfacial bond strength of the joint, thus the joint fails cohesively. At a slightly higher peel rate (Curve II), the tensile strength of the adhesive is still below the interfacial bond strength of the joint, so the joint still fails cohesively, but its tensile strain energy, and thus the observed peel force, is much greater than that of specimen I. The peel force for specimen II is the maximum force achievable for this adhesive system; that is, it corresponds to the liquid-like to rubber-like transition in figure 3. At a higher peel rate, (Curve III), the strength of the adhesive surpasses the interfacial strength of the joint and thus, the joint fails interfacially. The observed peel force for specimen III, however, is much less than that of specimen II, since specimen III's tensile strain energy is much lower than the tensile strain energy for specimen II.

\section{PEEL FORCE OF BUTYL-ADHERED EPDM JOINTS}

Short-time strength tests are the most common method for assessing the quality of an adhesive joint (for example, ASTM D 1876) and are an easy and convenient way to obtain results which may be useful in assuring seam quality. The objectives of the short-time strength experiments in this study were

* to determine whether the strength properties of joints adhered with two commercial butyl-adhesives are significantly different,

* to assess the sensitivity of joint strength to varying amounts of talc-like contaminants at different cure times,

* to determine the locus of failure for uncontaminated and contaminated joints,

* to determine the effect of adhesive thickness on peel strength at different cure times and contamination levels, and

* to determine if the peel strength of an EPDM butyl-adhered joint is more sensitive to adhesive thickness or to the presence of talc-like contaminants.

Each of these objectives is important in understanding the failure mechanisms and providing the technical basis for guidelines for the formation of reliable joints.

3. 1 Experimental

3.1.1 Materials

Two of the most widely-used commercial butyl-splicing adhesives were selected. The exact formulations of these adhesives were unknown, except that they 1) contained a complex blend of several different rubbers including an isocyanate 
component (Chmiel and Cotsakis, 1985), 2) had a low solidsfraction, and 3 ) had a low glass transition temperature.

Isocyanates cure in the presence of moisture and, thus, steps had to be taken to minimize the effects of adhesive pre-cure on the experimental results. To this end, the adhesive was removed from its bulk container at the beginning of the experiment and poured into a number of small containers, each of which was immediately sealed and only reopened when needed. The solids-fractions of the two adhesives were determined by heating three replicate samples of each in an oven at $100^{\circ} \mathrm{C}$ for 4 days. The average solids-fraction of Adhesive 1 was $29.6 \%$ with a standard deviation of the three replicates of $0.1 \%$; while that of Adhesive 2 was $29.0 \%$ with a standard deviation of the three replicates of $2.1 \%$ The glass transition temperatures of the adhesives and EPDM sheet were measured using a thermal mechanical analyzer equipped with an unloaded, $3.5 \mathrm{~mm}$ diameter probe and heated at a rate of 10 ${ }^{\circ} \mathrm{C} / \mathrm{min}$. The glass transition temperature of the cured adhesive was $-20{ }^{\circ} \mathrm{C}$, while that of the EPDM sheet was $-40^{\circ} \mathrm{C}$.

The $1.5 \mathrm{~mm}$ thick EPDM membrane material used in this experiment was from one sheet, which was cut into approximately 800 joint strips, each having dimensions of $25 \times 127 \mathrm{~mm}$. Each strip was cleaned by vigorously brushing both sides with soap and water, after which it was thoroughly rinsed with water. The cleanness of a strip was checked using the computer image processing procedure described below (see sec. 3.1.3). If the cleanness of the strip did not meet the predefined mean and standard deviation criteria, it was either recleaned or discarded.

After the strips were cleaned, they were matched into pairs, given an identification number, and randomly assigned to one of 10 treatments (that is, 2 adhesives $x 5$ levels of contamination). Each treatment contained 36 joint specimens.

\subsubsection{Specimen Contamination}

Within each pair of joint strips, one (designated side A) always remained clean, while the other (designated Side B) was contaminated. Contamination was achieved by moving a cleaned, Side B strip at constant velocity under an atomizer which uniformly sprayed the strip with a well-mixed, low concentration of commercial grade talc-like particles suspended in heptane (see Martin and Embree (1989) for a detailed discussion of this procedure). The talc-like particles were obtained from the manufacturer of the EPDM membrane material. Heptane was selected mainly because it is a hydrocarbon solvent, akin to the splice wash solvents commonly used in preparing field seams for

adhesion. It also had other desirable properties including high volatility and the ability to wet the surfaces of both the talc and the EPDM. The strips were contaminated to one of five levels corresponding to zero, two, four, six, and eight passes under the 
atomizer. The contamination levels were determined as described in the next section.

\subsubsection{Contamination Level Quantification}

The level of contamination of each strip was quantified using a computer image processing system, consisting of an 8-bit mini-computer-based image processor, a computer-controlled $\mathrm{X}-\mathrm{Y}$ positioning table, a camera, and a voltage-regulated fiber-optic tungsten light source (fig. 5). The principle underlying the measurement of cleanness or level of contamination is that the reflection of tungsten light from the black EPDM surface increases with increasing contamination of the surface by the whitish talc-like particles. Reflectance was quantified in terms of greyscale level, where a perfectly absorbing surface has a greyscale value of zero and a perfectly reflecting surface has a greyscale value of 255 . The intensity of the radiation was controlled by maintaining the electrical input into the fiberoptic light source at $120 \pm 0.3 \mathrm{~V}$ via a voltage regulator, and by fixing the positions of the optical fiber cables at approximately $15^{\circ}$ from the vertical axis of the camera. Calibration curves for relating greyscale value to the amount of talc-like particles deposited $\left(\mu \mathrm{g} / \mathrm{cm}^{2}\right)$ and procedures for insuring that the greyscale measurements remained in calibration are described in Martin and Embree (1989).

Greyscale values were measured for 20 areas, each having dimensions $5 \times 5 \mathrm{~mm}$, within the adhesion area of each $\mathrm{T}$-peel strip. From these 20 measurements, the average and standard deviation of the greyscale values were computed. If the standard deviation within a strip exceeded eight greyscale values, the strip was replaced with one which was more uniform. For the 360 Side A strips (the clean side of a $T$-peel joint), the average and standard deviation of the greyscale values were 33.0 and 2.8 , respectively. For the 360 side B strips (the contaminated side of a T-peel joint), the average greyscale values were $33,60,90$, 130, and 160 with a standard deviation of approximately 4.0. For comparison purposes, uncleaned commercial sheets of EPDM received directly from the manufacturer typically have greyscale values ranging from 170 to 250. (Hereinafter, strips cut directly from uncleaned, commercial sheet will be referred to as "as-received" strips.) Using analysis of variance techniques, no statistical difference at the 0.05 level of significance was found for the mean greyscale values for strips assigned to the two adhesives and at each contamination level.

\subsubsection{Specimen Preparation and Test Procedure}

Prior to applying the adhesive, the mass of each strip was determined. As subsequently discussed (see fig. 6), a highly linear relationship exists between adhesive mass and thickness. The mass of the adhesive, however, was experimentally easier to 
determine. In the text which follows, therefore, "adhesive mass" and "adhesive thickness" will be used interchangeably.

The butyl adhesive was applied to $75 \mathrm{~mm}$ of the strips comprising a joint beginning from one end of each strip. The adhesive was uniformly applied with a brush first to the clean strip (Side A) and then the contaminated strip (Side B), after which the brush was discarded. This procedure was adopted for every pair of strips to eliminate the transfer of talc. Once the adhesive was spread, the solvent was allowed to evaporate at laboratory conditions (approximately $24^{\circ} \mathrm{C}$ and $45 \%$ relative humidity) for approximately $30 \mathrm{~min}$. The strips were then joined and pressed in a hydraulic press at $700 \mathrm{kPa}$ (approximately 100 psi) for $10 \mathrm{~s}$ to form a T-peel joint. When the two adhesive layers were brought into contact with each other, the adhesive macromolecules interdiffused or coalesced resulting in the disappearance of the interfacial boundary between the two adhesive layers (Voyutskii 1963; Wake 1969). For these experiments, the start of the cure time was defined as the time at which a joint was removed from the press; 12 cure times (0.5, $1.0,1.5,2,4,6,24,48,96,192,768$, and $1320 \mathrm{~h}$ ) were used in this experiment. The joints were cured at $24^{\circ} \mathrm{C}$ and $45 \%$ relative humidity.

Three replicates were tested at each cure time, at each contamination level, and for each adhesive. The following information was collected for each replicate: T-peel strength, mass of the adhesive on the clean (Side A) and contaminated (Side B) strips, and the mode of adhesive failure. Peel strength was measured in a tensile testing machine at a crosshead speed of 50 $\mathrm{mm} / \mathrm{min}$.

The failure mode of a joint was assessed in two ways. The first was a visual assessment in which the failure mode was categorized as cohesive, interfacial (often termed adhesive failure), or a mixture of cohesive and interfacial failure. The second was a quantitative assessment based on the premise that the mass percent of adhesive remaining on the clean (Side A) strip depended on the contamination level of the Side B strip. Thus, if both the side A and B strips were clean, 50\% of the adhesive, on the average, should remain on the Side A strip; whereas, if the side B strip was heavily contaminated, then a disproportionately large amount of adhesive should remain on the Side A strip. The mass percent of adhesive on the Side A strip was determined by weighing the separated strips $\left(M_{\text {str-A }}+M_{\text {adh-A }}\right.$ and $\left.M_{\text {str }-B}+M_{\text {adh }-B}\right)$ and subtracting the initial mass of the $\operatorname{strips}\left(M_{\text {str-A }}\right.$ and $\left.M_{\text {str-B }}\right)$, from which both the mass of adhesive remaining on each strip ( $M_{\text {adh.A }}$ and $M_{\text {adh.B }}$ ) and the total mass of the adhesive remaining on both strips, $\mathrm{M}_{\text {adh }}$, could be determined. The mass percent of adhesive on the Side A strip, M' adh-A' was computed from 


$$
\mathrm{M}^{\prime}{ }_{\text {adh-A }}=\mathrm{M}_{\text {adh-A }} /\left(\mathbb{M}_{\text {adh-A }}+M_{\text {adh-B }}\right) \times 100 \text {. }
$$

A comparison was made between the visual and mass percent assessments from which it was ascertained that, on the average, a mass percent of $60 \%$ corresponded to cohesive failure, $75 \%$ corresponded to a mixture of cohesive and interfacial failure, and $90 \%$ corresponded to interfacial failure.

A separate set of joints was prepared for establishing the relationship between the mass $(g)$ of the adhesive, $M_{\text {adh }}$, and adhesive thickness, $T_{\text {adh }}$. The mass of the adhesive was measured according to the procedure discussed above. The adhesive thickness $(\mu \mathrm{m})$ was determined by subtracting the sum of the thicknesses of the individual joint strips from the thickness of the fully adhered T-peel joint measured after allowing it to cure for 2 weeks. All thickness measurements were made with a micrometer. The relationship between adhesive thickness and the mass of the adhesive applied to each strip over an area of $25 \mathrm{X}$ $75 \mathrm{~mm}$ was linear (see fig. 6), having the form

$$
\mathrm{T}_{\mathrm{adh}}=\mathrm{a}_{\mathrm{m}}+\mathrm{b}_{\mathrm{m}} \mathrm{M}_{\mathrm{adh}}
$$

where $a_{m}$ and $b_{m}$ are coefficients. Estimates of the coefficients for the fit of eq (8) were (1) $a_{m}=-29.83$ with the estimated standard error of the estimator of $7.29 ;$ (2) $\mathrm{b}_{\mathrm{m}}=554.85$ with the estimated standard error of the estimator of 21.66 . The standard error of the estimate, or residual standard deviation, was 10.35 and the squared correlation coefficient, $r^{2}$, for the fit of eq (8) to the adhesive mass data was $99.8 \%$

Since peel strength is known to be proportional to adhesive thickness ( variations in the adhesive thicknesses were not significantly different among the five contamination levels. An analysis of variance was conducted, from which it was concluded that the adhesive thicknesses were not significantly different between contamination levels at the 0.05 level of significance.

\subsection{Model of Strength Versus Cure Time}

An empirical model was presented in Martin and Embree (1989) for modeling changes in the peel strength with time; this model, called the Gompertz growth model, has the form

$$
s=s_{0} a^{b^{t}}
$$

where

$t$ is the cure time,

$S_{0}, a$, and $b$ are coefficients; $s_{0}$ represents the maximum achievable peel strength of $a$ joint; and $0<a<1$ and

$0<\mathrm{b}<1$. 
Equation 9 can be transformed into its more familiar distributional form (Ahuja \& Nash 1967), scaled by parameter $S_{0}$, by substituting

$$
-\alpha=\ln a
$$

and

$$
-\beta=\ln \mathrm{b}
$$

into eq (9), and obtaining

$$
S=S_{0} e^{-\alpha e^{-\beta t}}
$$

where $\alpha$ and $\beta>0$.

Although empirical, the coefficients of the model can be related to many of our experimental observations. For example, at $t=0$, eq (9) becomes

$$
\mathrm{S}=\mathrm{S}_{0} \mathrm{a}
$$

which is the minimum peel strength of the joint or equivalently, the cohesive strength of the butyl adhesive when the joint is first removed from the press. As $t \rightarrow \infty$, eq (9) becomes

$$
\mathrm{s}=\mathrm{S}_{\mathrm{o}}
$$

the maximum strength of the adhesive joint. The logarithm of the Gompertz parameter $b$ is the rate at which the logarithm of the logarithm of the scaled strength increases with cure time. This can be shown by taking the logarithm of both sides of eq (9)

$$
\ln s=\ln s_{0}+(\ln a) b^{t}
$$

substituting eq. (10) into eq (15),

$$
\left(\ln \mathrm{S}_{0}-\ln \mathrm{S}\right)=\alpha \mathrm{b}^{\mathrm{t}}
$$

and again taking the logarithm of both sides of eq (16)

$$
\ln \left(\ln s_{0}-\ln S_{)}=\ln \alpha+t \ln b\right. \text {. }
$$

Thus, the change in the logarithm of the difference in the logarithms of the maximum strength and the observed strength, $\ln \left(\ln s_{0}-\ln S_{)}\right.$, is linear with time.

\subsection{Results}

In a previous paper (Martin, Embree 1989), it was concluded that the strengths of joints adhered with the two commerciallyavailable adhesives were not significantly different at cure times greater than 6 hours. In this paper, the data for the 2 
adhesives are combined and reanalyzed and the effects of adhesive thickness on peel strength assessed.

\subsubsection{Failure Mode}

The mass percent of the adhesive adhering to the clean (Side A) strip is plotted against cure time at each of the five contamination levels in figure 7. For joints comprised of two clean strips (that is, greyscale equal to 33), failure was always cohesive; whereas for joints comprised of one contaminated and one clean strip, failure was cohesive for cure times of 2 hours or less, a mixture of cohesive and interfacial failure for cure times of 4 and 6 hours, and interfacial for cure times greater than 6 hours.

Scanning electron microscopy (SEM) was used to determine the locus of failure within a joint. In this analysis, the strips of the failed joint were opened like a book so that their common edges abutted and the failed surfaces of both strips could be imaged simultaneously by the SEM at low magnification (40X) (see fig. 9a). In addition, 100X magnification SEM micrographs of the Side $A$ and $B$ strips were made in the same area as the $40 \mathrm{X}$ micrographs (see figs. $9 \mathrm{~b}$ and 9c).

For uncontaminated joints and for joints cured for less than 2 hours, the joints failed cohesively and thus the locus of failure was within the adhesive layer (Location 1 in fig. 8). For joints containing a contaminated strip cured for longer than 6 hours (see fig. 9), the locus of failure was most often between a talc-like particle and the EPDM substrate (Location 3 in fig. 8 ) or between two stacked talc-like particles (Location 4 in fig. 8). Less often, the locus of failure was between a talc-like particle and the adhesive (Location 2 in fig. 8).

3.3.2 Effect of Adhesive Thickness on Peel Strength

From eq (5), peel strength $S$ should change linearly with adhesive thickness, and therefore, with adhesive mass $M_{\text {adh }}$, since the thickness of the adhesive and the mass of the adhesive are linearly related (see fig. 6); that is,

$$
S=a_{t k}+b_{t k} M_{a d h}
$$

where $a_{t k}$ and $b_{t k}$ are coefficients which are tabulated in table 1. From figure 10, the slope, $b_{t k}$, of the regression line was observed to be negative at short times and increase with cure time, eventually becoming positive. A negative slope was observed for joints cured for less than 2 hours (see fig. 10). This was believed to be due to the presence of solvents (Gent, Schultz 1972) or to the incomplete interdiffusion of the adhesive macromolecules between the two adhesive layers (Voyutskii 1963, 
1977). At intermediate cure times (cure times between 4 and 6 hours), the regression line is close to zero because of the transition from a negative to a positive slope; for this reason, the peel strength appears to be independent of adhesive thickness. At long cure times (cure times greater than 6 hours), peel strength increases with adhesive thickness as predicted by eq (5), except for the cure time at $192 \mathrm{~h}$ which was negative because of one outlying value for a specimen having a thick adhesive layer.

For contaminated joints, the trends in the $a_{t k}$ and $b_{t k}$ coefficients with cure time mimicked those for clean joints, except that the scatter in the coefficient estimates was greater. This scatter is believed to result from the confounding effects that surface contaminants have on peel strength. These confounding effects are discussed below.

Table 1. Peel strength versus adhesive mass coefficients for joints containing two cleaned strips
Cure Time
$a_{t k} \operatorname{se}\left(a_{t k}\right)^{*} \quad b_{t k}$
$\operatorname{se}\left(b_{t k}\right)$
$r^{2} \#$
(h)

\begin{tabular}{rrrrrr}
\hline 0.48 & 0.54 & 0.12 & -0.30 & 0.94 & 0.16 \\
0.96 & 0.66 & 0.07 & -0.32 & 0.38 & 0.13 \\
1.44 & 0.72 & 0.07 & -0.26 & 0.09 & 0.12 \\
1.92 & 0.89 & 0.06 & -0.36 & 0.07 & 0.87 \\
4.08 & 0.99 & 0.11 & -0.27 & 0.14 & 0.48 \\
6.00 & 0.72 & 0.16 & 0.22 & 0.22 & 0.19 \\
24.00 & 1.11 & 0.06 & 0.23 & 0.09 & 0.62 \\
48.00 & 1.14 & 0.17 & 0.55 & 0.27 & 0.52 \\
96.00 & 0.90 & 0.22 & 1.32 & 0.45 & 0.69 \\
192.00 & 2.05 & 0.11 & -0.93 & 0.25 & 0.78 \\
768.00 & 0.58 & 0.26 & 2.43 & 0.64 & 0.78 \\
1320.00 & 0.76 & 0.18 & 2.14 & 0.43 & 0.86
\end{tabular}

* se = estimated standard error of the estimator

\# $r^{2}=$ squared correlation coefficient

3.3.3 Strength versus Cure Time at Different Contamination Levels

Strength data at the five levels of contamination are plotted against cure time in figure 11. Superimposed on each data set is the predicted Gompertz growth curve (eq (9)), the parameters of which are shown in Table 2. In computing these 
statistics, the strength data were not corrected for adhesive thickness and thus, part of the variation observed in the peel strength data in figure 11 can be attributed to adhesive thickness variations.

The Gompertz parameters, $a, b$, and $s_{0}$, along with the predicted minimum peel strength, $S_{0} a$, are plotted against greyscale level in figure 12 and were fitted to the equations described below.

The estimated values of the Gompertz parameter a at the five contamination levels were modeled by

$$
a=a_{\max }\left(1-e^{-c G}\right)
$$

where

$G$ is the observed greyscale value,

$\mathrm{a}_{\max }$ is the asymptotic value of the Gompertz parameter a as greyscale value, $G$, approaches the maximum value of 255, and

$c$ is a coefficient which was chosen for best fit.

The estimated coefficients were $\mathrm{a}_{\max }=0.437$ with an estimated standard error of the estimator of 0.004 , and $c=0.0319$ with an estimated standard error of the estimator of 0.00115 . The squared correlation coefficient, $r^{2}$, was $99.5 \%$.

Table 2. Gompertz growth curve parameter estimates at each of the five contamination levels

\section{Gompertz growth curve parameters}

Nominal greyscale

$$
S_{0} \operatorname{se}\left(S_{0}\right)^{*}
$$

a $\quad$ se (a) b

se (b)

$r^{2} \#$

\begin{tabular}{llllllll}
\hline 33 & 1.573 & 0.021 & 0.286 & 0.014 & 0.911 & 0.008 & 0.96 \\
60 & 1.242 & 0.021 & 0.367 & 0.018 & 0.925 & 0.010 & 0.91 \\
90 & 1.021 & 0.018 & 0.419 & 0.023 & 0.898 & 0.018 & 0.87 \\
130 & 0.836 & 0.015 & 0.430 & 0.032 & 0.839 & 0.029 & 0.82 \\
160 & 0.703 & 0.019 & 0.432 & 0.052 & 0.767 & 0.054 & 0.64 \\
$* \begin{array}{l}\text { se = estimated standard error of the estimator } \\
r^{2}=\text { squared correlation coefficients }\end{array}$ & & &
\end{tabular}


The estimated values of the Gompertz parameter $b$, the rate of change in strength, remained relatively constant over the range of contamination levels studied, and were modeled by

$$
b=f\left(e^{-h G}-e^{-k G}\right)
$$

where

$G$ is the observed greyscale level and

$f, h$, and $k$ are coefficients which were selected for best fit.

The estimated coefficients were $f=1.069$ with an estimated standard error of the estimator of $0.0377, h=0.002$ with an estimated standard error of the estimator of 0.00029 , and $\mathrm{k}=$ 0.0705 with an estimated standard error of the estimator of 0.0105 . The squared correlation coefficient, $r^{2}$, was $97.4 \%$. Equation 20 is different from that originally proposed in Martin and Embree (1989). When the individual adhesives were analyzed, it appeared that the value of b remained constant at 0.94 .

The estimate values of the Gompertz parameter, $\mathrm{S}_{0}$, the maximum strength of a joint, at the five contamination levels were modeled by

$$
s_{0}=n e^{-p g}
$$

where

$G$ is the observed greyscale level, and

$\mathrm{n}$ and $\mathrm{p}$ are coefficients which were selected for best fit.

Estimates of the coefficients were $\mathrm{n}=1.857$ with an estimated standard error of the estimator of 0.0396 and $p=0.00615$ with an estimated standard error of the estimator of 0.00037 . The squared correlation coefficient, $r^{2}$, for the fit of eq (21) to the estimated $S$ o values was $99.4 \%$. From figure 12 , the maximum strength decreases by greater than $50 \%$ over the range of experimental contamination levels.

The minimum peel strength of a joint, $s_{0} a$, is the product of eqs (19) and (21) and has the form

$$
S_{o} a=q\left(e^{-r G}-e^{-s G}\right)
$$

where

$G$ is the observed greyscale level and

$q, r$, and $s$ are coefficients. 
The estimated coefficients were $q=0.681$ with an estimated standard error of the estimator of $0.058, r=0.00497$ with an estimated standard error of the estimator of 0.000628 , and $\mathbf{s}=$ 0.0409 with an estimated standard error of the estimator of 0.00863 . The squared correlation coefficient, $r^{2}$, for the fit of eq (15) to the estimated s。a data was $99.3 \%$

\subsection{Discussion}

From figure 11, it can be seen that the Gompertz growth curves fit the strength data well and that the strengths of the two adhesives are not significantly different.

A comparison of the sensitivities of peel strength to contamination and adhesive thickness can be made from figures 10 and 12, respectively. From figure 10, at long cure times, the difference in the strength of joints at long cure times and over the range of adhesive thickness is $0.2 \mathrm{kN} / \mathrm{m}$ (approximately 1 lbf/in). From figure 12, the maximum strength, $s_{0}$ of the peel joints decreased by more than 50\% over the range of contamination levels; that is, strength decreased by approximately $0.9 \mathrm{kN} / \mathrm{m}$ (5.1 l bf/in) over the experimental range of contamination levels. Thus, contaminants affect peel strength to a much greater extent than adhesive thickness.

Superimposed on figure 12 are the peel strengths for joints fabricated from an "as-received" strip (that is, from a strip cut from a commercial EPDM membrane), which had greyscale values greater than 200 and which were cured for longer than $48 \mathrm{~h}$.

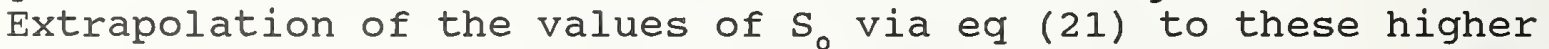
"as-received" greyscale levels resulted in a predicted strength which was greater than the observed strengths. This discrepancy may be due to the non-uniform distribution of contaminants on the surface of the "as-received" strips or from cleaning the surface of the laboratory prepared strips prior to applying the contaminants.

From the visual inspection and SEM micrographs, contaminants appear to act by blocking the formation of adhesive bonds with the EPDM substrate. The presence of contaminants reduces the effective load-carrying width of a joint ( $W$ in eq (5)). Based on this assumption, our results can be graphically explained using Gent and Petrich's approximation model. In figure 13, only one stress-strain curve for the adhesive is displayed, since the peel rate was kept constant. The interfacial strength of the joints (the horizontal lines in fig. 13) decreases with increasing contamination, since the contaminants effectively reduce the joint width and thereby, the load-carrying ability of the joints. For clean joints, the tensile strength of the adhesive was less than the interfacial bond strength of the joint, so the joints failed cohesively. For contaminated joints, the tensile strength 
of the adhesive exceeded the interfacial strength, so the joints failed interfacially. As the level of contamination increased, the interfacial strength of the joint decreased and, with this decrease, peel strength decreased.

\subsection{Peel Strength Conclusions}

The sensitivity of the strength in peel of butyl-adhered EPDM joints to surface contaminants, adhesive thickness, cure time, and adhesive type were experimentally determined. From the experimental results and for the range of conditions covered by them, it is concluded that:

1. The gain in strength with cure time for clean and contaminated joints can be predicted using the Gompertz growth model.

2. For cure times less than 2 hours, the strengths of clean and contaminated joints depend on the cohesive strength of the butyl adhesive and not on the level of contamination.

3. For cure times greater than 2 hours, the interfacial strength of butyl-adhered EPDM joints was highly dependent on contamination level and the contaminated joints failed interfacially. We believe that the contaminants act by preventing the adhesive from bonding with the substrate, thus effectively reducing the load-carrying width of a joint.

4. The maximum achievable strength, $S_{0}$, for butyl-adhered EPDM joints occurs when both strips are clean. The maximum peel strength of joints containing one contaminated and one clean strip decreased to half of the strength of our clean joints over the range of experimental contamination levels.

5. Surface contaminants decrease the peel strength of our peel joints more than adhesive thickness increases strength.

6. No significant difference was observed in the strengths of the two commercial butyl adhesives at long cure times.

\section{CREEP-RUPTURE TIMES-TO-FAILURE OF BUTYL-ADHERED EPDM JOINTS}

The major difference between short-time strength and creeprupture experiments is one of strain rate. We believe that the low strain rates inherent in creep-rupture experiments are more representative of the strain rates experienced by an in-service, field-formed seam. To date, few creep-rupture experiments have been performed (Martin et al. 1987); instead, short-time strength experiments are preferred (Westley 1982; Dupuis 1983; Rossiter et al. 1988; and Watanabe and Rossiter 1990). Before the results of short-time peel strength experiments are accepted, it is important to insure that the effects of each experimental 
variable on the short-time strength and on the creep-rupture life a're the same. Otherwise, performance requirements may be imposed which have little to do with the in-service performance of roofing seams.

The objectives of the creep-rupture time-to-failure experiments were

* to determine the effect of contamination level, adhesive thickness, cure time, and mechanical load on the creeprupture life of butyl-adhered EPDM joints stressed in peel,

* to determine the failure mode of the contaminated and uncontaminated joints,

* to derive a mechanistically-based model for predicting the time-to-failure of a joint stressed in peel, and

* to compare the rankings of the principal experimental variables as they affect short-time peel strength with the corresponding rankings for creep-rupture times-to-failure.

\subsection{Experimental}

The experimental procedure for the creep-rupture experiments was basically the same as that used in the short-time strength experiments. Therefore, only differences are highlighted.

\subsubsection{Materials}

Six hundred pairs of EPDM peel strips were randomly assigned to one of 20 treatment combinations ( 5 contamination levels $\times 4$ mechanical loads). Each treatment combination was applied to 30 replicate joints. The five levels of contamination were the same as those used in the short-time strength experiments; that is, the average greyscale levels were 33, 60, 90, 130, and 160. The four creep-rupture loads were $0.154,0.231,0.308$, and 0.386 $\mathrm{kN} / \mathrm{m}$. Only one adhesive, the one designated Adhesive 1 in the short-time strength experiment, was used, since the performance of the two commercial adhesives used in the short-time strength experiment was not significantly different, especially at long cure times. The other experimental materials, the methods for cleaning and contaminating the surface of the peel strips, the procedure for quantifying the level of contamination, and the methods for preparing the joints were the same as those described in section 3.1, except that the experimental materials came from a different production lot.

\subsubsection{Experimental Procedure}

The creep-rupture apparatus was designed to load 120 joints at once; thus, the 600 joints were separated into five batches. In creating a batch, one contamination level was randomly selected for each of the four mechanical load levels. The joints within each batch were randomly assigned to the 120 positions in 
the apparatus. The starting and ending times of the joints were monitored electronically. The starting time was the same for all of the joints assigned to a batch; the ending time, however, was unique to each joint and occurred when the strips completely separated. Separation caused the deactivation of the electronic clock assigned to that joint and the recording of its time-tofailure. The accuracy of the recorded time-to-failure was within 1 second. All of the creep-rupture experiments were conducted at $24{ }^{\circ} \mathrm{C} \pm 1{ }^{\circ} \mathrm{C}$ and $45 \% \pm 2 \%$ relative humidity.

Prior to the start of a new batch, all of the joints in the batch currently under load were allowed to fail; hence, the cure times differed from batch-to-batch. (The cure times for the five batches in this experiment were 1224, 1562, 1825, 2161, and 2449 $h$, respectively). It was assumed that differences in cure time did not adversely affect the chemical or physical stability of a joint. To test this hypothesis, three joints were randomly selected from each of the four treatments assigned to a batch and their short-time strengths determined using the procedure described in section 3.1.4. The remaining 27 joints within each treatment or, equivalently, 108 joints within each batch (27 joints per treatment $x 4$ treatments per batch) were loaded to their assigned creep-rupture load and the time-to-failure of each joint observed. Besides time-to-failure, the following data were collected for each creep-rupture joint: 1) a visual assessment of the failure mode, 2) the mass of the adhesive remaining on both the clean (Side A) and the contaminated (Side B) strips, and 3) the mass percent of the adhesive remaining on the clean (Side A) peel strip.

4.2 Results

4.2.1 Peel Strength at Long Cure Times

The peel strengths, $S$, of the joints removed for short-time strength determination from each contamination-mechanical load treatment were determined at the end of the creep-rupture experiment. The strengths of the joints within each contamination level were then plotted against cure time (see fig. 14) and fitted to a linear regression model of the form

$$
s=a_{t}+b_{t} t
$$

where $a_{t}$ and $b_{t}$ are coefficients, the values of which are shown in Table 3 along with an estimated standard error of the estimators and the mean strength for all of the joints having the same level of contamination. 
Table 3. Creep-Rupture Results--Linear regression coefficients for changes in strength with cure time. The cure times ranged from $1224 \mathrm{~h}$ to $2449 \mathrm{~h}$. The coefficients are computed in units of $\mathrm{kN} / \mathrm{m}$. $\underset{\text { greyscale }}{\operatorname{nominal}} \quad a_{t} \quad \operatorname{se}\left(\mathrm{a}_{\mathrm{t}}\right)^{*} \quad \mathrm{~b}_{\mathrm{t}} \quad \mathrm{se}\left(\mathrm{b}_{\mathrm{t}}\right)^{*} \quad \mathrm{H}_{\mathrm{o}}: \mathrm{b}_{\mathrm{t}}=0^{\#} \quad \mathrm{x}_{\mathrm{t}} \pm \underset{(\mathrm{kN} / \mathrm{m})}{\mathrm{s}^{+}}$

$33 \quad 1.61 \quad 0.072-2.10 \times 10^{-5} 3.75 \times 10^{-5}$ accept $\mathrm{H}_{0} 1.57 \pm 0.27$

$60 \quad 1.560 .15-2.98 \times 10^{-5} 8.10 \times 10^{-5}$ accept $H_{0} 1.50 \pm 0.26$

$90 \quad 1.270 .124 .60 \times 10^{-5} 6.37 \times 10^{-5}$ accept $H_{0} 1.36 \pm 0.24$

$130 \quad 1.08 \quad 0.10 \quad 5.23 \times 10^{-5} 5.88 \times 10^{-5}$ accept $\mathrm{H}_{0} 1.16 \pm 0.20$

$160 \quad 1.430 .21 \quad 2.10 \times 10^{-5} 1.00 \times 10^{-4}$ accept $H_{0} 0.99 \pm 0.17$

* se = estimated standard error of the estimator

\# $\mathrm{H}_{0}: \mathrm{b}_{\mathrm{t}}=0$. Null hypothesis, $\mathrm{H}_{\mathrm{o}}$, that the slope of the regression line, $b_{t}$, is different from zero at the 0.05 level of significance.

$+\mathrm{x}_{\mathrm{t}} \pm \mathrm{s}=$ the mean and standard deviation in the strengths of all joints assigned to a contamination treatment level.

The stability of the joints was assessed by determining if the slope of the regression line, $b_{t}$, was significantly different from zero. Using a standard statistical analysis procedure (the student $t$ test), at the 0.05 level of significance, the strengths of the joints assigned to each contamination level did not change significantly between 1224 to $2449 \mathrm{~h}$ of cure, an outcome consistent with that predicted by the proposed strength versus cure time model (eq (9)).

The mean strengths for the creep-rupture joints are plotted against contamination level in figure 15 and the values compared with the maximum strength estimates, $s_{0}$, for the short-time strength experiments. From figure 15, the mean strengths of the clean joints (greyscale $=33$ ) were the same in both experiments, but the mean strength of the contaminated creep-rupture joints were higher than the corresponding mean strengths from our shorttime strength experiments. The reason for this discrepancy is not understood.

\subsubsection{Failure Mode}

The rate of peel of all of the creep rupture joints was highly s, that is, no stick-slip behavior was observed. The mass percent of the adhesive adhering to the clean (Side $A$ ) strips is plotted against time-to-failure in figure 16. From visual 
Table 4. Creep Rupture Results--Linear regression coefficients and estimated standard error of the estimators for changes in the mass percent of the adhesive remaining on Side A versus cure time at each contamination and mechanical load level

$\begin{array}{lllllll}\text { contam. load } & a_{A} & \operatorname{se}\left(a_{A}\right)^{*} & b_{A} & \operatorname{se}\left(b_{A}\right) & H_{0}: b_{A}=0^{\#} & x_{A} \pm s_{A}+ \\ \text { lev. } & \text { lev. }\end{array}$

\begin{tabular}{rrrrrrrr}
\hline 33 & 1 & 47.67 & 1.38 & 0.03 & 0.02 & accept & $49.7 \pm 2.6$ \\
33 & 2 & 48.33 & 1.72 & 0.05 & 0.10 & accept & $49.1 \pm 2.8$ \\
33 & 3 & 50.65 & 1.87 & -0.04 & 0.30 & accept & $50.4 \pm 2.3$ \\
33 & 4 & 48.73 & 1.20 & 0.26 & 0.23 & accept & $49.6 \pm 2.3$ \\
60 & 1 & 50.36 & 0.79 & 0.17 & 0.01 & reject & $51.6 \pm 2.4$ \\
60 & 2 & 54.15 & 2.27 & -0.15 & 0.17 & accept & $52.2 \pm 3.1$ \\
60 & 3 & 50.14 & 2.04 & 0.33 & 0.32 & accept & $52.8 \pm 2.4$ \\
60 & 4 & 53.18 & 2.11 & -0.13 & 0.56 & accept & $52.7 \pm 2.6$ \\
90 & 1 & 53.51 & 0.92 & 0.01 & 0.02 & accept & $54.1 \pm 2.6$ \\
90 & 2 & 53.04 & 1.37 & 0.10 & 0.12 & accept & $54.1 \pm 2.5$ \\
90 & 3 & 54.14 & 1.70 & 0.15 & 0.33 & accept & $54.9 \pm 2.0$ \\
90 & 4 & 58.79 & 2.03 & -1.11 & 0.71 & reject & $55.2 \pm 3.7$ \\
& & & & & & & \\
130 & 1 & 58.5 & 1.63 & -0.10 & 0.04 & reject & $54.8 \pm 3.4$ \\
130 & 2 & 54.6 & 2.16 & 0.26 & 0.23 & accept & $57.0 \pm 2.8$ \\
130 & 3 & 55.5 & 4.31 & 0.46 & 0.93 & accept & $57.6 \pm 6.1$ \\
130 & 4 & 77.8 & 5.02 & -5.93 & 1.84 & reject & $61.9 \pm 4.8$ \\
160 & 1 & 66.8 & 1.87 & -0.12 & 0.04 & reject & $60.9 \pm 4.1$ \\
160 & 2 & 70.4 & 1.51 & -0.87 & 0.14 & reject & $61.9 \pm 5.3$ \\
160 & 3 & 77.4 & 3.33 & -2.89 & 0.87 & reject & $66.5 \pm 4.1$ \\
160 & 4 & 85.2 & 3.06 & -7.12 & 1.23 & reject & $68.0 \pm 5.4$
\end{tabular}

* se = estimated standard error of the estimator

\# $\mathrm{H}_{\mathrm{o}}: \mathrm{b}_{\mathrm{A}}=0$. Result of testing the null hypothesis that the slope of the regression line, $b_{A}$, is zero at the 0.05 level of significance.

$+\mathrm{x}_{\mathrm{A}} \pm \mathrm{s}_{\mathrm{A}}=$ the mean and standard deviation of the mass percent adhesive remaining on the clean (side A) strip for the joints assigned to a contamination/mechanical load level. 
inspection of the failed peel strips and from the mass percent measurements (see criteria in sec. 3.1.4), it was concluded that all the creep-rupture joints failed cohesively regardless of their level of contamination or applied mechanical load.

To determine if the mass percent of adhesive remaining on the clean (Side A) strip depended on the time-to-failure of a joint, the data were fitted to a linear regression equation of the form

$$
M_{A d h \cdot A}=a_{A}+b_{A} t
$$

where $a_{A}$ and $b_{A}$ are coefficients, the values of which are tabulated in Table 4 along with an estimated standard error of their estimators and the average and standard deviation of the mass percent of the adhesive remaining on the clean (Side $A$ ) strip within each treatment level. A statistical analysis was performed (the student $t$ test) to determine if the slope of the regression line, $b_{A}$, was different from zero at the 0.05 level of significance. From this analysis, the null hypothesis that the slopes were zero could not be rejected, except at very high levels of contamination where the slopes were negative. As discussed in the next section, contaminants only affected highly contaminated joints having short times-to-failure and thin adhesive layers.

\subsubsection{Creep-Rupture Times-to-Failure}

The dependence of the time-to-failure on applied stress has been studied for a wide variety of materials including metals, polymers, and polymeric fibers (Bartenov and zuyev 1968; Martin 1982). From the analysis of the creep-rupture data for these materials, two empirical models have repeatedly been found to fit the time-to-failure data, $\tau$, as a function of applied stress, $\sigma_{0}$. The general forms of these models are as follows:

$$
\tau=a_{e} \exp \left(-b_{e} \sigma_{o}\right) \quad \text { \{the "exponential model"\} }
$$

and

$$
\tau=a \sigma_{0}^{-b} \quad \text { \{the "power law model" }
$$

where $a_{e}, b_{e}, a$, and $b$ are coefficients. For joints stressed in peel, the applied stress, $\sigma_{\circ}$, is given by (see eq. (5))

$$
\sigma_{\circ}=\left(4 \mathrm{PE} \mathrm{adh}_{\mathrm{adh}} / \mathrm{WT}_{\mathrm{adh}}\right)^{1 / 2}
$$

where, for the present, it is assumed that Young's modulus, $E_{\text {adh }}$, and the width of a joint, $W$, are constants, while the creeprupture load, $\mathrm{P}$, and the thickness of the adhesive, $\mathrm{T}_{\text {adh }}$, are measurable variables. 
From the literature, the exponential model tends to provide a better fit to the time-to-failure data for polymers stressed at temperatures below their glass transition temperature; while the power law model tends to provide a better fit to the time-tofailure data for polymers stressed at temperatures above their glass transition temperature (Martin 1982). However, this glass transition temperature criterion is not inviolate, since, for example, some researchers have used the exponential model to obtain satisfactory fits to the time-to-failure data for polymers stressed above their glass transition temperature (Martin, 1982). For this reason, the time-to-failure data were fitted to both models and a selection was made between the two models on the basis of their fit to the data, even though our experiments were conducted at a temperature well above the glass transition temperatures of both the membrane and adhesive.

becomes

Substituting eq (27) into eq (25), the exponential model

$$
\tau=a_{e} \exp \left(-b_{e}\left(4 \mathrm{PE}_{\mathrm{adh}} / W \mathrm{~T}_{\mathrm{adh}}\right)^{1 / 2}\right)
$$

Taking the logarithm of both sides of eq (28),

$$
\log _{10} \tau=\log _{10} a_{e}-2.303 b_{e}\left(4 P E_{a d h} / W T_{a d h}\right)^{1 / 2}
$$

which can be simplified further to

$$
\log _{10} \tau=\log _{10} a_{e}-b_{e}^{\prime}\left(P / T_{a d h}\right)^{1 / 2}
$$

when $E_{a d h}$ and $W$ are assumed constant and where

$$
\mathrm{b}_{e}^{\prime}=2.303 \mathrm{~b}_{\mathrm{e}}\left(4 \mathrm{E}_{\mathrm{adh}} / \mathrm{W}\right)^{1 / 2} \text {. }
$$

The power law model can be reformulated by substituting eq (27) into eq (26) yielding

$$
\tau=\mathrm{a}\left(4 \mathrm{PE}_{\mathrm{adh}} / \mathrm{WT}_{\mathrm{adh}}\right)^{-\mathrm{b} / 2} \text {. }
$$

Taking the logarithms of both sides and using the simplifying assumptions, eq (31) becomes

$$
\log _{10} \tau=a^{\prime}-b / 2 \log _{10} P / T_{a d h}
$$

where $\mathrm{a}^{\prime}=\log _{10} \mathrm{a}-\mathrm{b} / 2 \log _{10} 4 \mathrm{E}_{\mathrm{adh}} / \mathrm{W}$.

In figure 17, both the exponential and the power law models are fitted to all of the time-to-failure data (number of joints = 540). The power law model (eq (31)) fit the time-to-failure data much better than did the exponential model. The coefficient estimates of the power law model (eq (31)) are (1) $a^{\prime}=1.10$ with an estimated standard error of the estimator of 0.007 , (2) $\mathrm{b}=5.13$ with an estimated standard error of the estimator of 
0.034. The standard error of the estimate, the residual standard deviation, is 14.2 and the squared correlation coefficient, $r^{2}$, for the fit of eq (31) to the time-to-failure data is $91.3 \%$.

The power law model, eq (31), predicts that the time-tofailure of a joint decreases with an increase in the mechanical load and/or a decrease in the thickness of the adhesive. The dependence of the times-to-failure on mechanical load is welldocumented (Martin et al. 1982; Bartenev et al. 1969). The dependence of the times-to-failure on adhesive thickness are presented in figure 18. From figure 18a, it is evident that the time-to-failure of a peel joint could be greatly increased by even incrementally increasing the mass (and, thereby, the thickness) of the adhesive. To verify this prediction, three joints, comprised of two cleaned strips and having very thick adhesive layers, were prepared and subjected to a mechanical load of $0.308 \mathrm{kN} / \mathrm{m}$. The masses of the adhesive at the time-of-failure of each joint were $0.69,0.79$, and $0.83 \mathrm{~g}$ and the times-tofailure were 1030, 1469, and $788 \mathrm{~h}$, respectively. These timesto-failure are much greater than the times-to-failure predicted by substituting the adhesive mass into the power law model (the predicted times-to-failure were 99, 140, and $159 \mathrm{~h}$ respectively), indicating that the power law model underestimates the real

improvement in the creep-rupture life of joints when the adhesive thickness is increased.

Contaminants may also affect the time-to-failure of a joint (see fig. 16). It was assumed that contaminants reduce the effective load carrying width of a joint in proportion to the level of contamination. Thus, the joint width term, $W$, in eq (31) was modified as follows:

$$
W_{\text {effective }}=C_{1} W\left(G_{\max }-G_{\text {act }}\right) / G_{\max }
$$

where $0<\mathrm{c}_{1}<1$ and where

$$
\begin{aligned}
& \mathrm{G}_{\text {act }}=\text { observed contamination level and } \\
& \mathrm{G}_{\max }=\text { maximum level of contamination for all the } \\
& \text { experimental joints (here, } \mathrm{G}_{\max }=170 \text { ). }
\end{aligned}
$$

Substituting eq (33) into eq (31) and taking the logarithms of both sides yields an equation of the form:

$\log _{10} \tau=b_{1}+b_{2} \log _{10}\left[\left(G_{\max }-G_{a c t}\right) / G_{\max }\right]+b_{3} / 2 \log _{10}\left[P / T_{a d h}\right]$

where $b_{1}=\log _{10} a-b / 2 \log _{10} 4 \mathrm{E}+\mathrm{b} / 2 \log _{10} c_{1} \mathrm{~W}$. Estimates of the coefficients in eq (34) (number of joints $=540$ ) are (1) $b_{1}$ $=1.28$ with an estimated standard error of the estimator of 0.0068 , (2) $b_{2}=-1.89$ with an estimated standard error of the estimator of 0.017 , and (3) $b_{3}=-0.02$ with an estimated standard error of the estimator of 0.01 . The residual standard deviation is 0.10 and the squared correlation coefficient, $r^{2}$, is 
$95.8 \%$. The effect of contaminants on time-to-failure is statistically significant, but, relative to the thickness of the adhesive and the mechanical load, the effect of contaminants on the creep-rupture life of a joint is minor.

\subsection{Discussion}

The debonding of all of the creep-rupture peel joints progressed at a constant velocity; that is, the peeling process was stable. The times-to-failure of our adhesively bonded joints are highly dependent on the magnitude of the mechanical load and adhesive thickness and to a much lesser extent on surface contamination. This ranking of variables is different from that for our short-time strength results which were highly dependent on the level of contamination, and to a much lesser extent, on the thickness of the adhesive. This transposition in the ranking of adhesive thickness and contamination results from the differences in peel rates between short-time strength and the creep rupture experiments.

At low strain rates, the adhesive exhibits liquid-like flow behavior. The tensile strength of the adhesive is small and, for our experimental conditions, the tensile strength of the adhesive never exceeds the interfacial bond strength of the adhesive to the substrate; that is, the joints fail by cohesion. Graphically, these results can be explained using Gent and Petrich's approximation model. As the level of contamination increases, the interfacial strength of the joints decreased, as shown by the horizontal lines in figure 19. The effect of increasing the creep-rupture load is equivalent to increasing the strain rate of the adhesive; the effect of which is represented by the four stress-strain curves in figure 19. Since all of the creep-rupture joints failed cohesively, the stress-strain curve corresponding to the highest mechanical load must be below the lowest interfacial strength line. Presumably, if the joints had been contaminated to a higher level, the strength of the adhesive would have eventually exceeded the interfacial strength of the joint resulting in interfacial failure.

\subsection{Creep-Rupture Time-to-Failure Conclusions}

The creep-rupture sensitivity of butyl-adhered EPDM joints to surface contaminants, adhesive thickness, cure time, and mechanical load were experimentally determined and the significance of each factor on time-to-failure ranked. From the creep-rupture data, for the range of experimental conditions, it is concluded that:

1. The strengths of the creep-rupture joints remained constant over the range of experimental cure times. 
2. The failure mode for all the creep-rupture joints was cohesive regardless of contamination level or applied mechanical load. The rate of crack-growth for the creep-rupture peel joints was also highly s; that is, no stick-slip behavior was observed.

3. A mechanistically based model, depending on mechanical load, contamination level, and adhesive thickness, was derived and fitted to the creep-ripture data. The fit of the model to the data was quite good and from this analysis, it was concluded that the creep-rupture life mainly depends on mechanical load and adhesive thickness and to a lesser extent on contamination level. Thus, the ranking in importance of the two principal experimental variables (level of contamination and adhesive thickness) in the creeprupture experiment were reversed from their ranking in the short-time strength experiment. This reversal is attributed to changes in the rheological properties of the adhesive when stressed at different peel rates.

4. Performance requirements for seams should be based on creep-rupture results as opposed to short-time strength results.

5. COMPARISON OF TIMES-TO-FAILURE FOR BUTYL-AND NEOPRENEADHERED EPDM JOINTS AS A FUINCTION OF LOAD RATIO

It is common in engineering practice to minimize the probability of failure of a structural element by assigning a

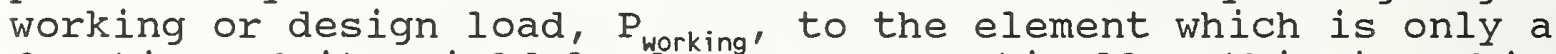
fraction of its yield load, Pyield. Practically, this is achieved by reducing the yield load by a factor of safety, Fs; that is,

$$
F S=\mathrm{P}_{\text {yield }} / \mathrm{P}_{\text {working }}
$$

where in industrial applications, it is typical to apply factors of safety whose product is between one and three (Boresi et al. 1978). (Applied loads are directly proportional to the applied stresses; thus, the working load and yield load can just as easily be expressed as a working stress and yield stress.) The factors of safety account for unexpectedly high in-service loads and for reductions in the resistance properties of a structural element resulting from statistical variations in the material properties and from variations introduced during fabrication (see for example, Ellingwood et al. 1980). For viscoelastic structural materials (such as wood, geosynthetic materials, and seams in EPDM roofing membranes), the greatest reduction factor compensates for the creep-rupture effect; that is, the ability of viscoelastic materials to sustain only a fraction of their yield loads for sustained periods of time. 
Table 5. Creep-Rupture Results--Stress ratios and the mean and standard deviations of the times-to-failure for the butyl- and neoprene-adhered EPDM creep-rupture joints. Data for the neoprene-adhered EPDM joints was published in Martin, Embree, and Bentz (1987)

\begin{tabular}{lllcccc}
\hline contam. & stress & mech. & avg. & stress & mean & std. dev. \\
greyscale & lev. & load & strength & ratio & ttf & ttf \\
level & & $(\mathrm{kN} / \mathrm{m})$ & $(\mathrm{kN} / \mathrm{m})$ & $(\%)$ & $(\mathrm{h})$ & $(\mathrm{h})$
\end{tabular}

butyl-adhered EPDM

$\begin{array}{rrrrrrr}33 & 1 & 0.154 & 1.57 & 10 & 66.60 & 25.60 \\ 33 & 2 & 0.231 & 1.57 & 15 & 15.70 & 5.30 \\ 33 & 3 & 0.308 & 1.57 & 20 & 6.14 & 1.30 \\ 33 & 4 & 0.386 & 1.57 & 25 & 4.80 & 1.90 \\ 60 & 1 & 0.154 & 1.50 & 10 & 77.10 & 52.50 \\ 60 & 2 & 0.231 & 1.50 & 15 & 13.00 & 3.70 \\ 60 & 3 & 0.308 & 1.50 & 21 & 6.41 & 1.13 \\ 60 & 4 & 0.386 & 1.50 & 26 & 3.65 & 0.89 \\ 90 & 1 & 0.154 & 1.36 & 11 & 48.40 & 31.00 \\ 90 & 2 & 0.231 & 1.36 & 17 & 10.70 & 4.00 \\ 90 & 3 & 0.308 & 1.36 & 23 & 4.94 & 1.19 \\ 90 & 4 & 0.386 & 1.36 & 28 & 2.81 & 0.77 \\ 130 & 1 & 0.154 & 1.16 & 13 & 35.40 & 14.10 \\ 130 & 2 & 0.231 & 1.16 & 20 & 9.06 & 2.35 \\ 130 & 3 & 0.308 & 1.16 & 27 & 4.50 & 1.44 \\ 130 & 4 & 0.386 & 1.16 & 33 & 2.70 & 0.43 \\ 160 & 1 & 0.154 & 0.99 & 16 & 49.07 & 18.80 \\ 160 & 2 & 0.231 & 0.99 & 23 & 9.72 & 4.65 \\ 160 & 3 & 0.308 & 0.99 & 31 & 3.75 & 0.78 \\ 160 & 4 & 0.386 & 0.99 & 39 & 2.42 & 0.56\end{array}$

neoprene-adhered EPDM

$\begin{array}{lllllr}33 & 1 & 0.080 & 0.75 & 11 & 199.5 \\ 33 & 2 & 0.155 & 0.75 & 22 & 5.8 \\ 33 & 3 & 0.235 & 0.75 & 31 & 1.3 \\ 33 & 4 & 0.315 & 0.75 & 42 & 0.6\end{array}$


The reduction factor for creep-rupture is found by plotting the mean time-to-failure of a roofing seam against the applied load ratio, $\mathrm{LR}=\mathrm{P}_{\text {applied }} / \mathrm{P}_{\text {yield! (or equivalently, the stress ratio) }}$ and selecting that load ratio (stress ratio) having a mean timeto-failure which is equal to or greater than the expected design life of the component. In figure 20, the load ratios of several viscoelastic building materials are plotted against mean time-tofailure (the data for the butyl-and neoprene-adhered EPDM peel joints are shown in table 5).

From figure 20, the stress ratio versus mean time-to-failure plots are greater for 1) semi-crystalline materials, such as wood stressed in bending (Wood, 1951) and high density polyethylene (HDPE) stressed in lap-shear (Halse et al. 1989), than for 2) amorphous materials, such as neoprene and butyladhered EPDM seams loaded in peel at temperatures far above their glass transition temperatures. For example, wood has been tested down to $65 \%$ and HDPE to $45 \%$. Straight-line extrapolation of the wood and HDPE curves would indicate that wood is able to sustain approximately $60 \%$ of its short-time stress while HDPE can only sustain $20 \%$ for a design life of 10 years. On the other hand, curve-line extrapolation of neoprene- and butyl-adhered EPDM peel joint data indicate that these materials can only sustain $5 \%$ of their yield load for this period of time. Thus, it is concluded from figure 20 that the reduction factors for creep-rupture are the same for both neoprene-and butyl-adhered EPDM seam joints when stressed in peel and that only a very small peel load is required to cause in-service seam failures.

\section{SUMMARY}

The most frequently reported defect in EPDM single-ply roofing systems occurs in the field-formed seams. Seam defects occur most often within the first 3 years after installation of the roof and may result from weaknesses in the materials, deficiencies in the fabrication technique, or as a result of environmental stresses. The objectives of this study were to determine the importance of several material and fabrication variables as they affect the short-time strength and creeprupture life of butyl-adhered EPDM joints stressed in peel and, where possible, to derive mechanistically based models. The joints were stressed in peel because this stress mode has been implicated in several commonly observed field-formed seam defects. This is not to imply that peel stresses cause all seam defects, for other stress modes (e.g., lap shear) may also be important.

From the short-time strength experimental results, joints failed cohesively for cure times less than 2 hours, failed cohesively and interfacial failure for cure times between 4 and 6 hours, and failed interfacially for cure times greater than 6 
hours. The gain in strength of the joints as a function of cure time was modeled with the Gompertz growth curve equation. From the analysis of our strength data, peel strength was highly dependent on cure time and the level of contamination and to a lesser extent on adhesive thickness.

From the creep-rupture experimental results, the joints always failed cohesively regardless of the level of contamination or the magnitude of the mechanical load. A mechanistically based model, which was functionally dependent on mechanical load, adhesive thickness, and contamination level, was fitted to the time-to-failure data. Times-to-failure were highly dependent on mechanical load and adhesive thickness and to a much lesser extent on the level of contamination. One prediction of this model was that an increase in the thickness of the adhesive layer above the experimental thicknesses could result in a great increase in the service life of a joint.

Although the magnitude of the peel loads to which fieldformed seams are subjected are unknown, it is possible to determine from the creep-rupture results the upper limit of peel stresses which can be sustained by a joint over time. Our experimental results indicate that butyl and neoprene-adhered EPDM joints stressed in peel can only sustain less than 5\% of their yield stresses over the design life of a roof. Thus, field-formed seams should be designed to minimize peel loads. Where this is not possible, our results indicate that the service life of seams can be significantly improved by minimizing the magnitude of the peel loads and increasing the thickness of the adhesive and, to a lesser extent, by insuring the cleanness of the seams.

Our experimental results have identified several fabrication (surface cleanness), material (adhesive thickness and cure time), and stress (peel load magnitude) variables as having a

significant effect on the service life of EPDM roof seams. As everyone knows, who works with materials, especially building materials, the variables examined in this experiment are only a subset of the material, fabrication, design and stress variables which may affect the service life of EPDM seams. In future experiments, the other variables can be interjected to determine which have a significant effect on a roofing seam's service life.

\section{ACKNOWLEDGMENTS}

The authors acknowledge the help of their colleagues, Jack Lee and John Winpigler, for their invaluable assistance in helping to conduct the experiments and, willard Roberts, for measuring the glass transition temperatures of the EPDM membrane and the butyl adhesive. 
Ahuja, J.C. and Nash, S.W. (1967) "The generalized GompertzVerhulst family of distributions," Sankhya, Series A 29:141.

ASTM D 1876, (1983) "Standard test method for peel resistance of adhesives (T peel test)," Annual Book of ASTM Standards, Vol 15.06, ASTM, Philadelphia, PA.

Bartenev, G.M. and Zuyev, Yu. S. (1968) Strength and Failure of Visco-Elastic Materials. Pergamon, New York.

Boresi, A.P., Sidebottom, O.M., Seely, F.B., and Smith, J.O. (1978)

Advanced Mechanics of Materials, Wiley, New York.

Box, G.E.P., Hunter, W.G., and Hunter, J.S. (1978) Statistics for Experimenters, Wiley, New York.

Bright, W.M. (1954) "The adhesion of elastomeric pressuresensitive adhesives: rate processes," in Adhesives and Adhesion, J. Clark, J.E. Rutzler, and R.I. Savage [Eds.], Wiley, New York.

Chmiel, C.T. and Cotsakis, D.J. (1985) "Adhesive for bonding cured EPDM rubber," U.S. Patent 4,501,842.

Cullen, W. (1984) "Survey compares practices to problems" Roofing Spec. $12(10), 37$.

Cullen, W. (1988) "Project pinpoint: NRCA's diagnostic database." Prof. Roofing 16(7), 17.

Cullen, W. (1989) "Interest runs high in project pinpoint's data bank." Prof. Roofing 17(7), 29.

Dregger, P. and Ellingson, W. (1988) "What seams to be the problem." Roofer Magazine 8(2): 35.

Dupuis, R.M. (1983) "Analysis and design of adhesive lap splices for elastomeric single-ply membranes." Proc. 7th conf. on Roofing Technology, Joint National Bureau of Standards/National Roofing contractors Association Symposium, held at NBS, Gaithersburg, MD.

Ellingwood, B., Galambos, T.V., MacGregor, J.G., and Cornell, C.A. (1980) "Development of a probability based load criterion for American National standard A58," National Bureau of Standards NBS Spec. Publ. 577.

Ferry, J.D. (1961) Viscoelastic Properties of Polymers, Wiley, New York. 
Gent, A.N. and Hamed, G.R., (1977) "Peel mechanics of adhesive joints," Polym. Eng. Sci. 17(7): 462-466.

Gent, A.N. and Hamed, G.R. (1978) "Adhesion of elastomers, with special reference to triblock copolymers," Rubber Chem. Tech. 51: 354 .

Gent, A.N. and Hamed, G.R. (1982), "Some rheological aspects of the peel strength of rubbery adhesives," Rubber chem. Tech. $55(2): 483-493$.

Gent, A.N. and Petrich, R.P. (1969) "Adhesion of viscoelastic materials to rigid substrates," Proc. Roy. Soc. A, 310: 433-448.

Halse, Y.H., Koerner, R.M., and Lord, A.E., Jr. (1989)

"Laboratory evaluation of stress cracking in HDPE geomembrane seams," in Durability and Aging of Geosynthetics, R.M. Koerner [ed.], Elsevier, New York, p. 177.

Johnson, J.E., Dupuis, R.M., and Lee, J.W. (1977) "Physical properties of BUR membranes tested at low rates of loading," Proc. of the Symposium on Roofing Technology, Joint NBS/NRCA Symposium held in Washington, D.C., sept. 21-23.

Kaelble, D.H. (1960) "Theory and analysis of peel adhesion: bond stresses and distributions," Trans. Soc. Rheology 4: 45-73.

Kaelble, D.H. (1964) "Theory and analysis of peel adhesion: rate-temperature dependence of viscoelastic dependence of viscoelastic interlayers," J. Colloid Sci. 19: 413 .

Kaelble, D.H. (1965) "Peel adhesion: micro-fracture mechanics of interfacial unbonding of polymers," Trans. Soc. Rheo. 9(2): 135163.

Kaelble, D.H., (1971), Physical Chemistry of Adhesion, Wiley, New York, pp 423-432.

Lord, A.E. and Halse, Y.H. (1989) "Polymer durability -- the materials aspects," in Durability and Aging of Geosynthetics, R.M. Koerner [ed.], Elsevier, New York, p 293.

Martin, J.W. (1982) "Time transformation functions commonly used in life testing analysis," Dur. Building Mat. 1: 175-194.

Martin, J.W. and Embree, E. (1989) "Effects of contaminants and cure time on EPDM single-ply joint strength." J. Mat. Civ. Eng. $1(3): 151$. 
Martin, J.W., Embree, E., and Bentz, D.P. (1987) "Effect of temperature and stress on the time-to-failure of EPDM T-peel joints." Proc. 8th Conf. on Roofing Technology, Joint NBS/NRCA Conference held at the National Institute of standards and Technology, Gaithersburg, MD 20899, April 16-17, 1987.

Niesiolowski, F. and Aubrey, D.W. (1981) "Stress distribution during peeling of adhesive tapes," J. Adhesion 13: 87-98.

Rossiter, W.J. (1987) "Tests of adhesive-bonded seams of singleply rubber membranes," Roofing Research and standards

Development, ASTM STP 959, R.A. Critchell [ed.], American Society for Testing and Materials, Philadelphia, pp 53-62.

Rossiter, W.J. (1988) "Further investigation of the effect of application parameters on adhesive-bonded seams of single-ply roof membranes." Materials and structures 21: 243.

Rossiter, W.J. and Seiler Jr., J.F. (1988) "Report of roof inspection: partial delamination of adhesive-bonded seams at an army facility." National Institute of standards and Technology NISTIR 88-3893.

Rossiter, W.J. and Seiler, Jr., J.F. (1989) "Results of a survey of the performance of EPDM roofing at army facilities." National Institute of Standards and Technology NISTIR 89-4085.

Russo, M. (1988) "Single-ply seaming: the state of the art." Roofing/siding/Insulation $65(8): 20$.

Stucker, N.E. and Higgens, J.J., (1977) "Butyl Rubber and Polyisobutylene," Chap. 16, Handbook of Adhesives, I. Skeist [ed.], Van Nostrand, New York.

Voyutskii, S.S. (1963) Autohesion and Adhesion of High Polymers, Interscience, New York.

Voyutskii, S.S. and Ustinova, Z.M., (1977) "Role of autohesion during film formation from the latex," J. Adhesion 9: 39-50.

Wake, W.C., (1969), "Elastomeric adhesives," in Treatise on Adhesion and Adhesives, Vol. 2, Materials, R.L. Patrick [ed.], Marcel Dekker, NY.

Watanabe, H. and Rossiter, W.R. Jr. (1990) "Effects of adhesive thickness, open time, and surface cleanness on the peel strength of adhesive-bonded seams of EPDM rubber roofing membranes," to be published in Roofing Research and Standards Development, 2nd Volume, T.J. Wallace and W.R. Rossiter [eds.], ASTM STP 1088, American Society for Testing and Materials, Philadelphia, PA. 
Westley, S.A. (1982) "Bonding ethylene propylene diene monomer roofing membranes: the theory and practice of adhering

vulcanized ethylene propylene diene to itself." in Single-ply Roofing Technology, ASTM STP 790, Gompertz, W.H. [ed.], American Society for Testing and Materials, pp 90-108.

Wood, L.W. (1951) "Relation of strength of wood to duration of load," USDA Forest Service Paper No. 1916.

Wu, S. (1982) Polymer Interface and Adhesion, Marcel Dekker, New York. 


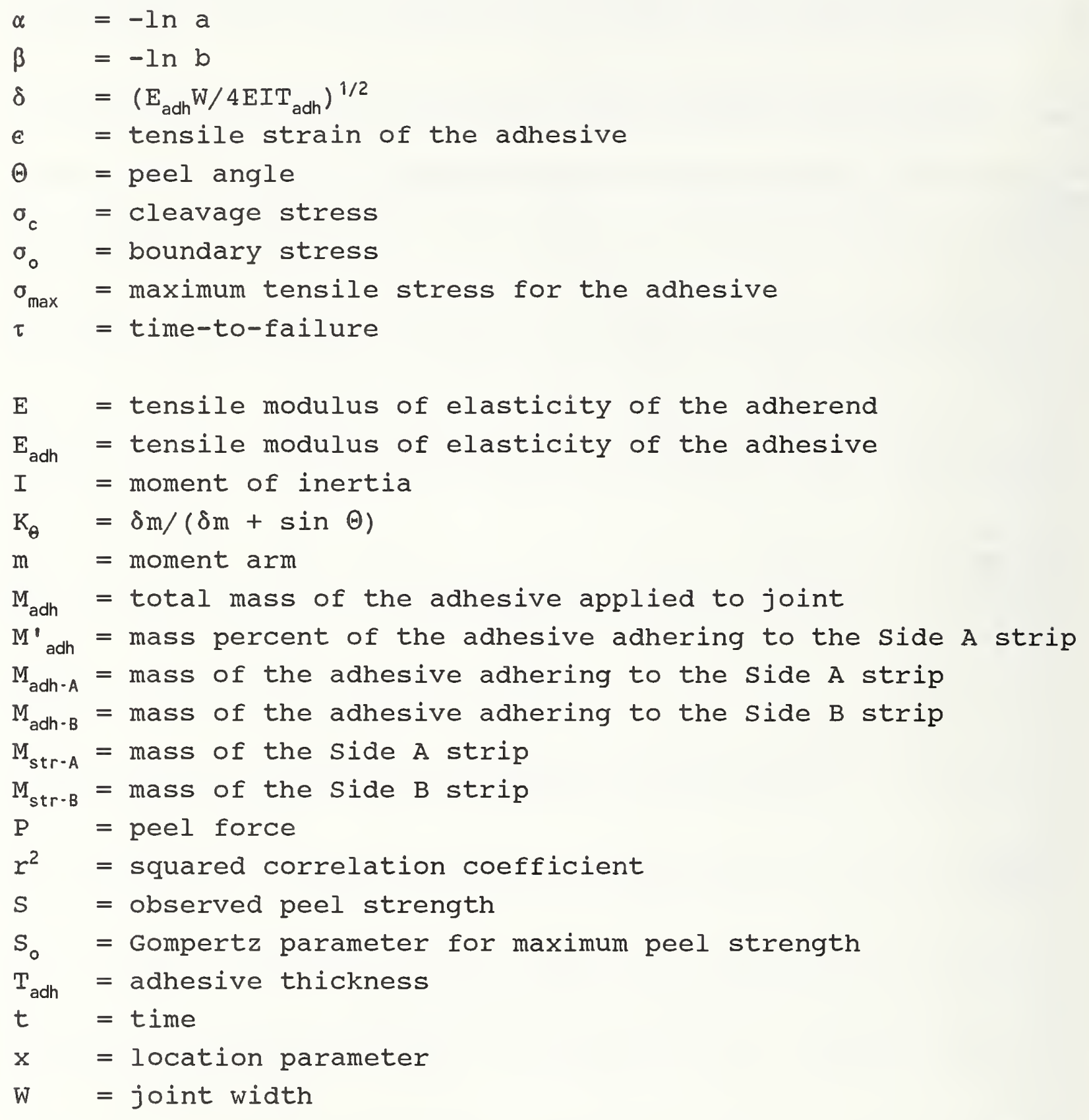



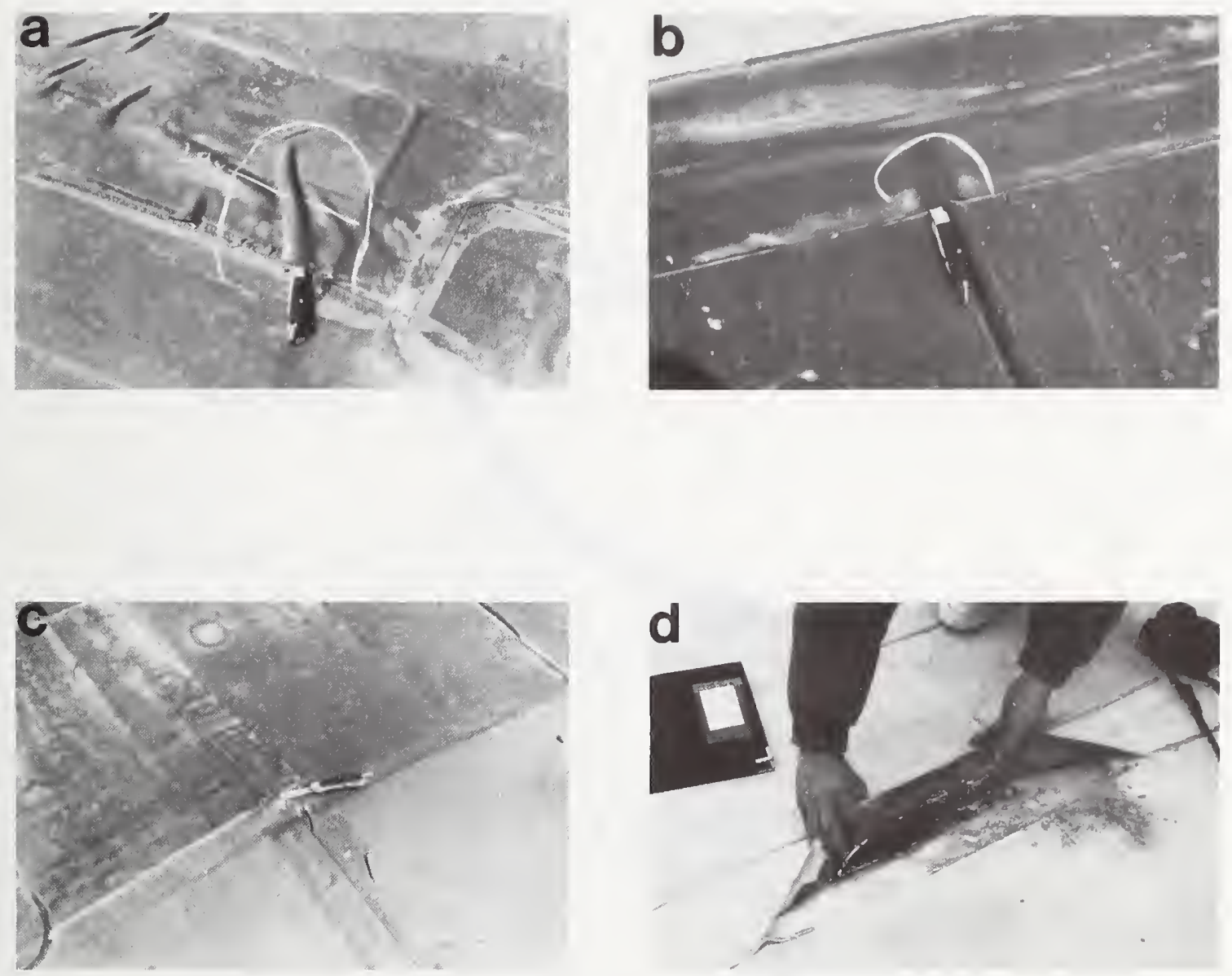

Figure 1. Seam defects in which a peel-type failure mode is implicated: $a, b)$ ripples in the EPDM membrane and c) T-joint. It is not clear what the failure mode is for the seam defect pictured in d). 


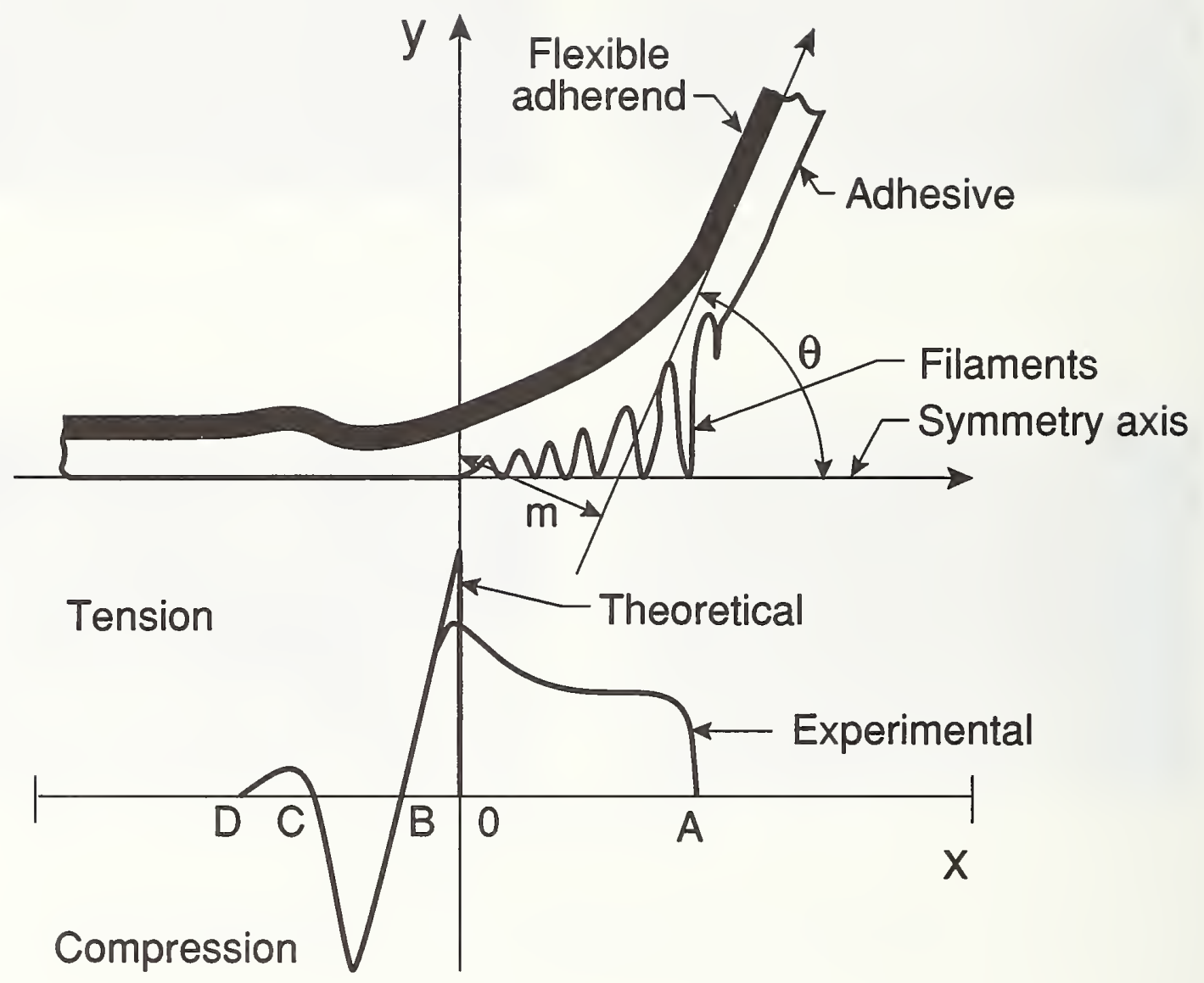

Figure 2. Distribution of stresses along upper half of peel specimen. 


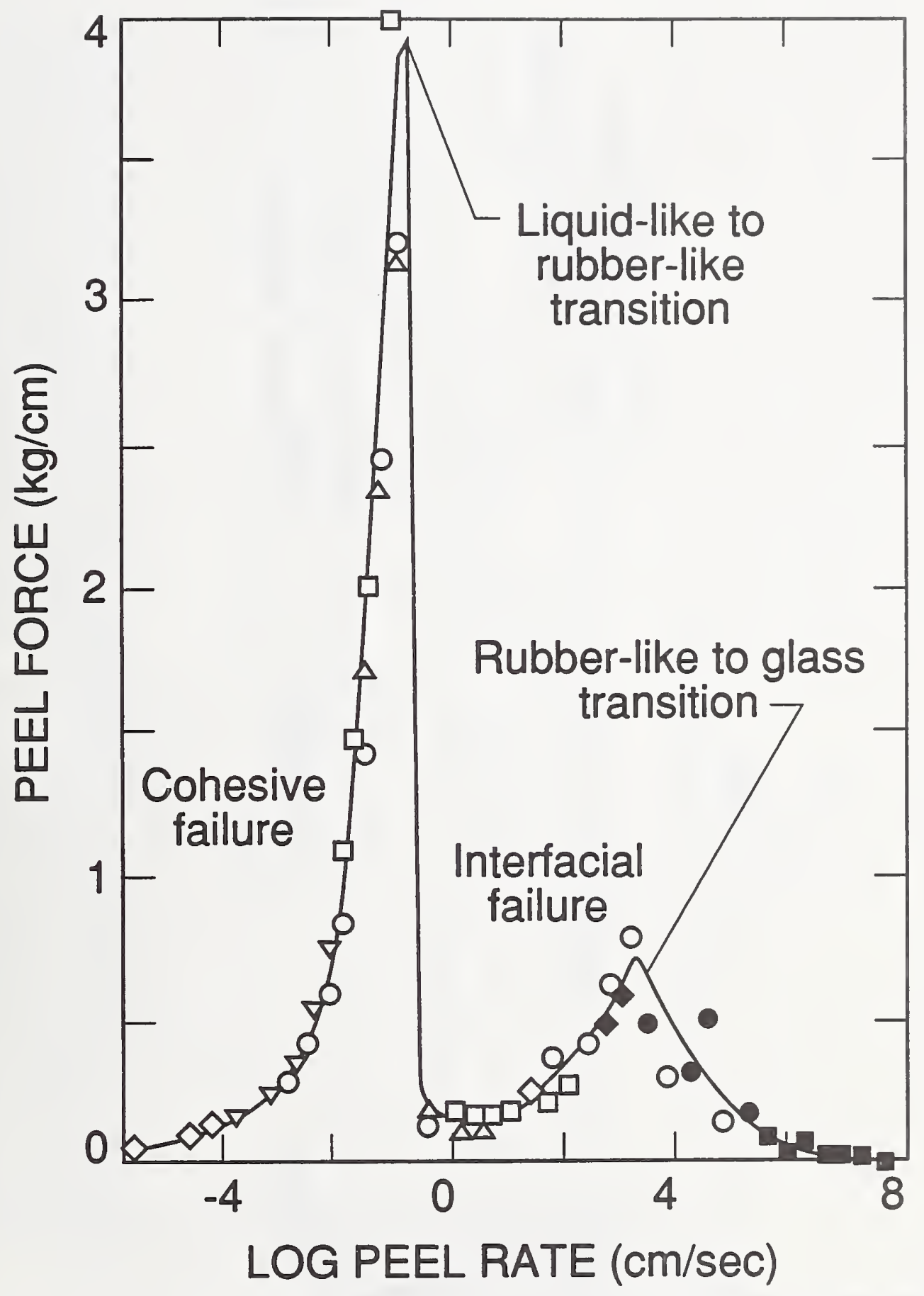

Figure 3. Typical peel force versus peel rate diagram for a flexible adherend adhesively bonded with an uncrosslinked elastomeric adhesive (after Gent and Petrich, 1969). 


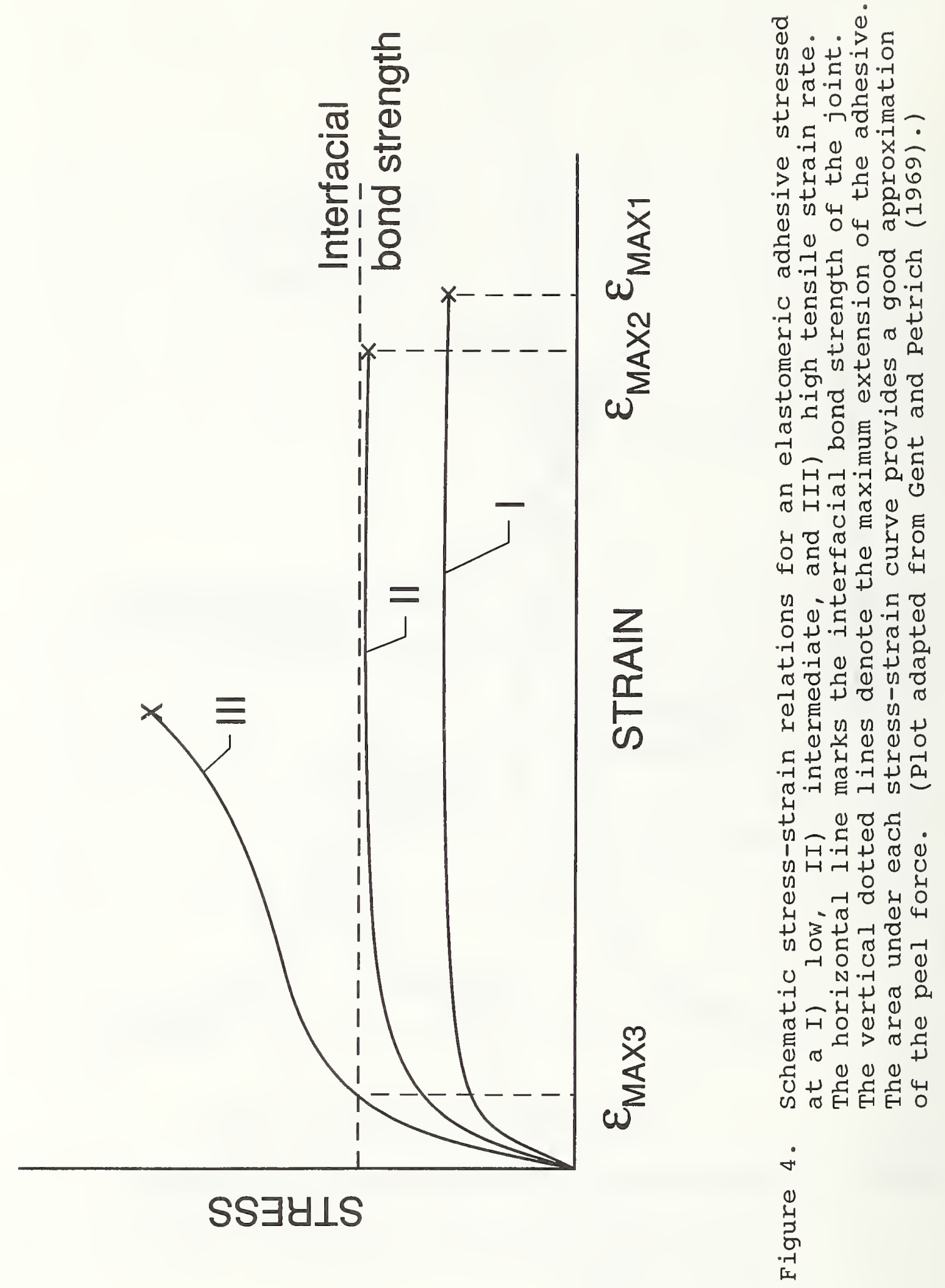




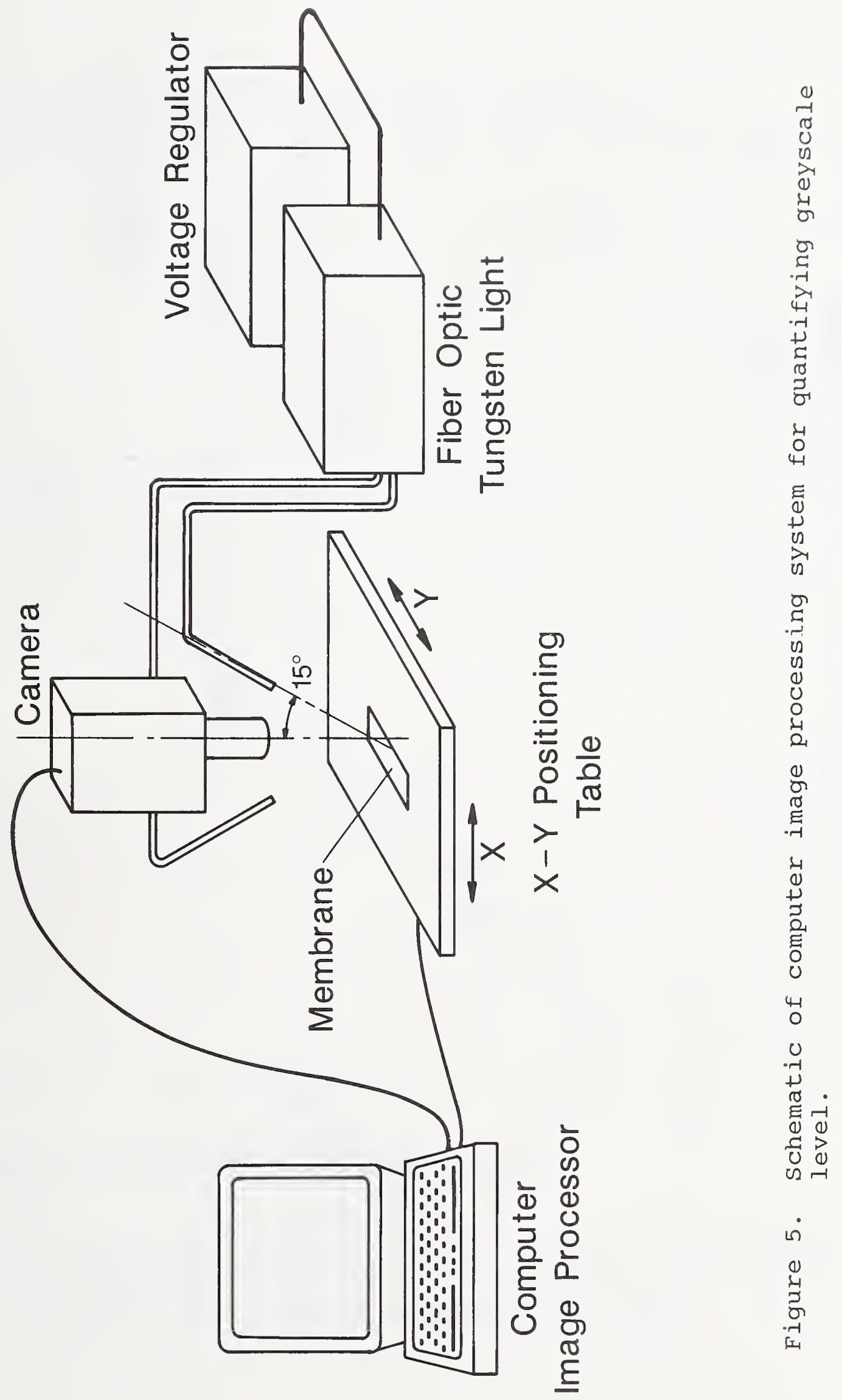




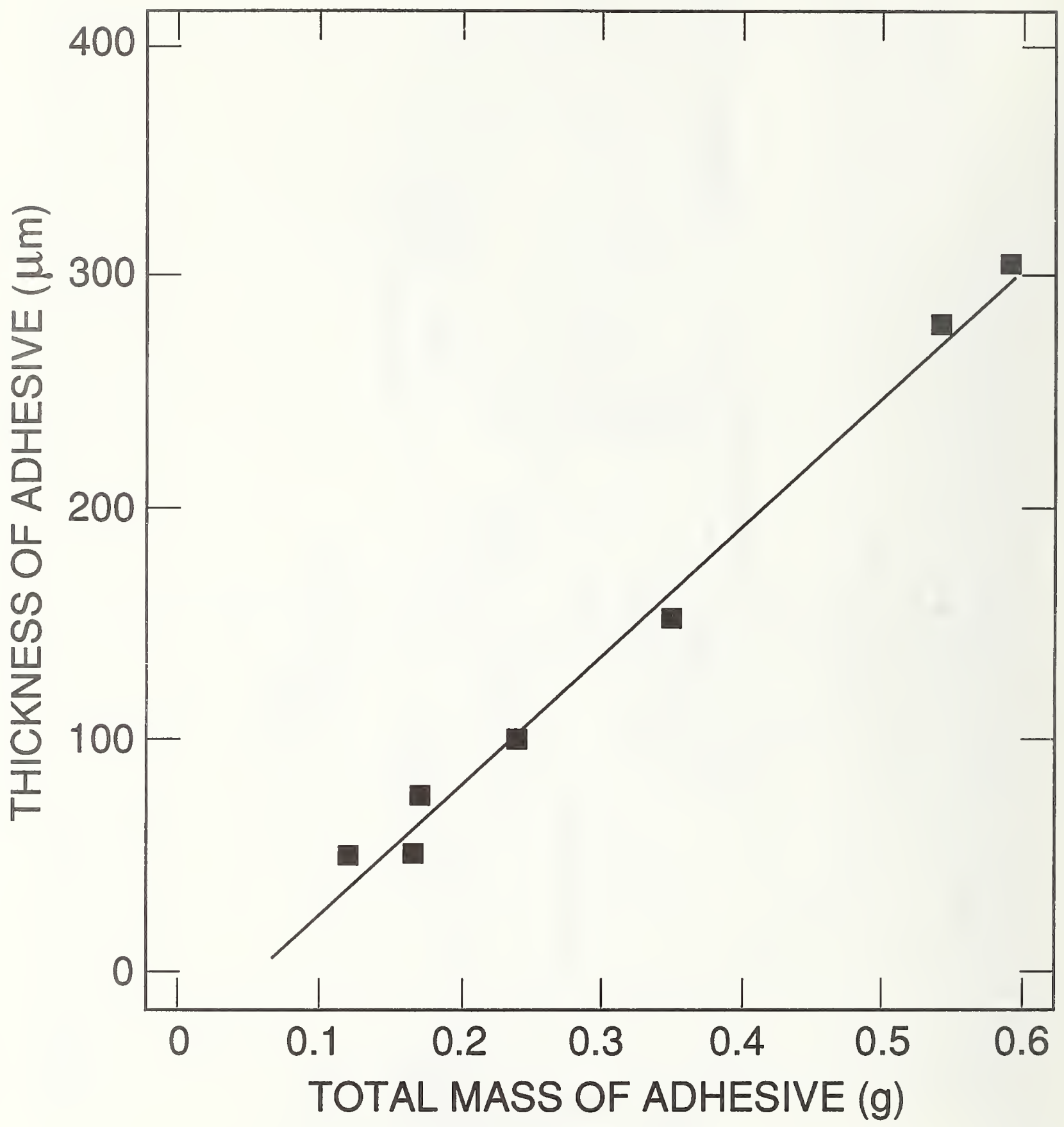

Figure 6. Calibration curve for adhesive thickness versus adhesive mass. Joints cured for two weeks prior to making measurements. 

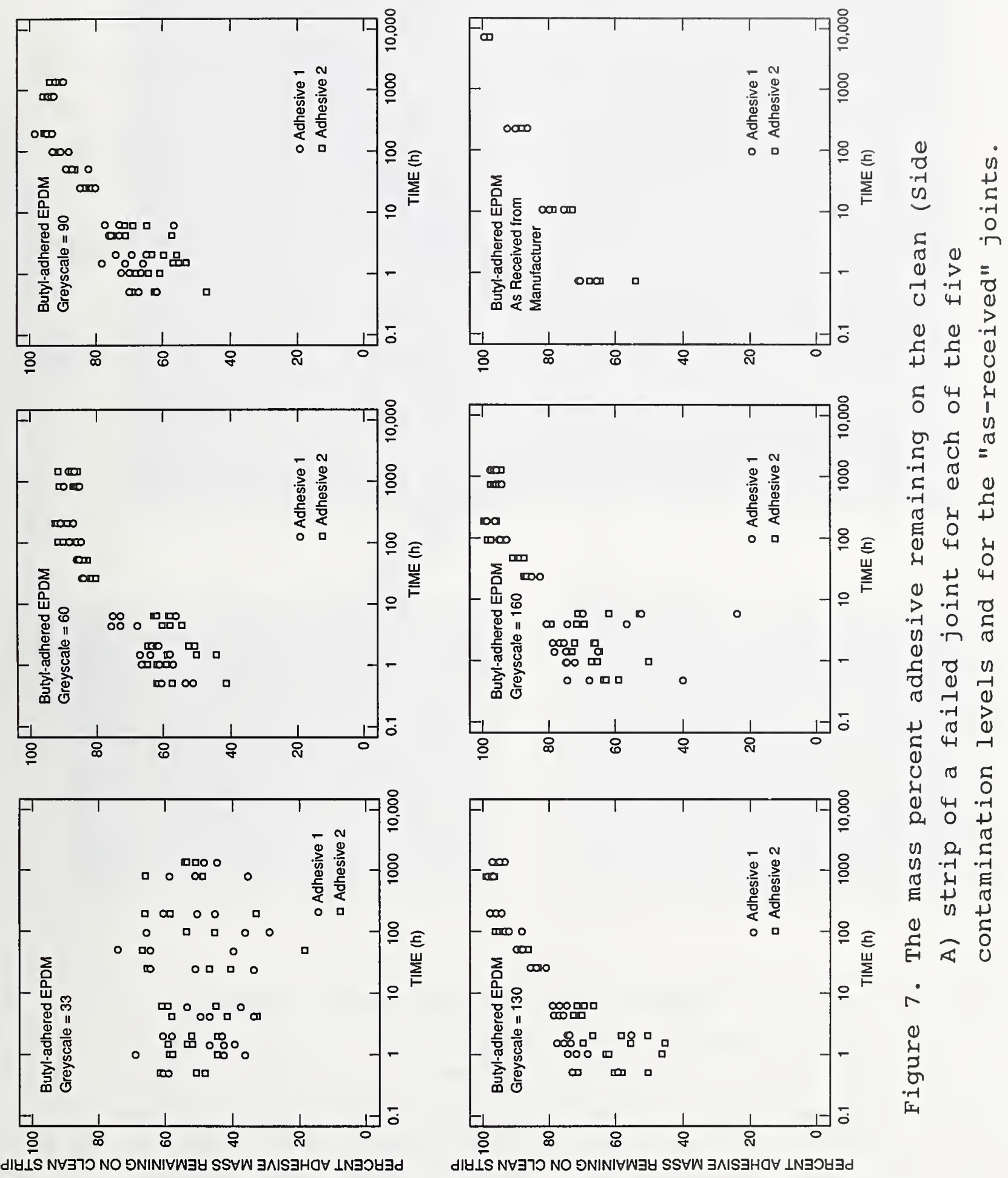


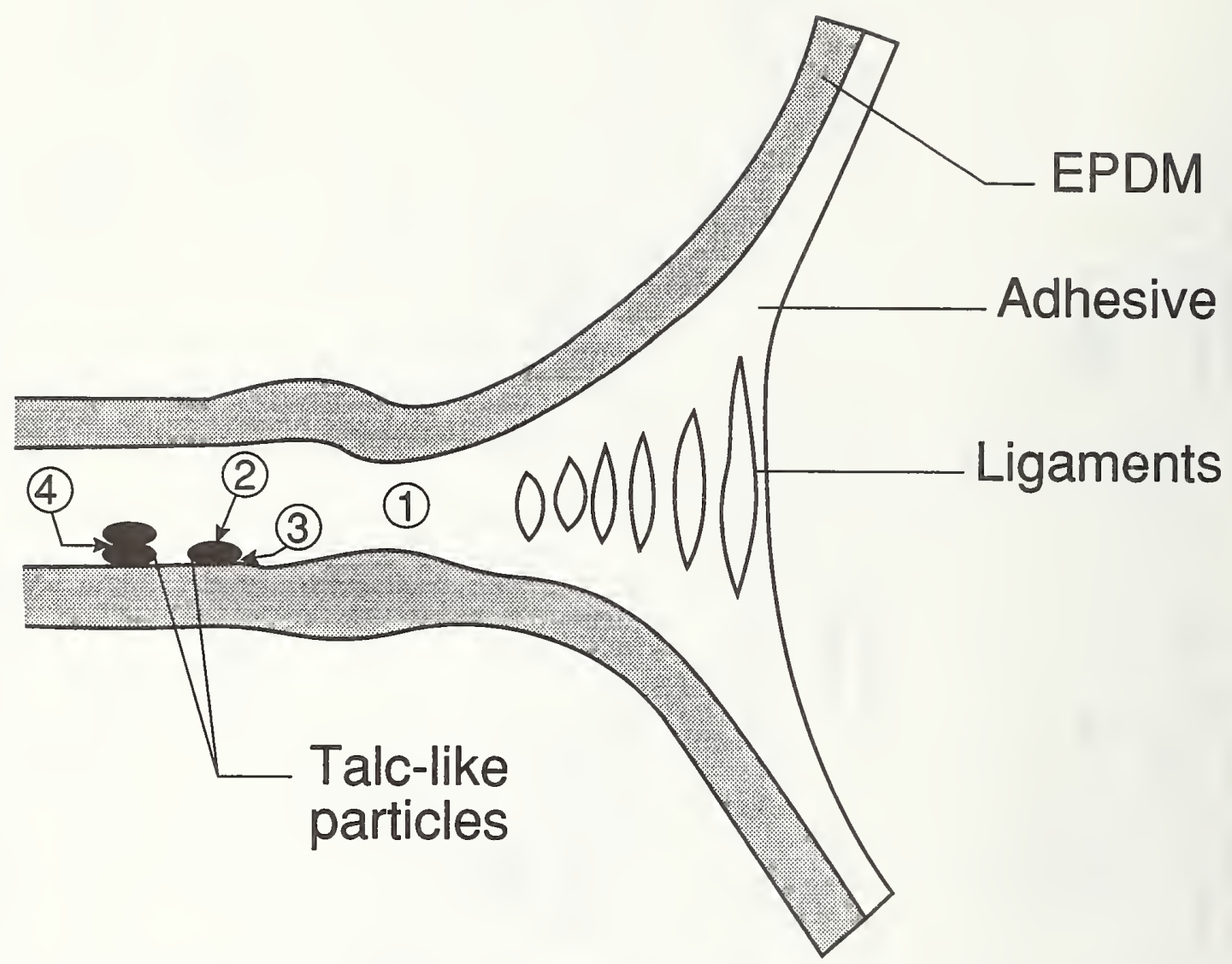

Figure 8. Schematic representation of failure locations: 1) failure within the adhesive layer which is typical in the case of cohesive failure, 2) failure at the adhesive/talc-like particle interface, 3) failure at a talc-like particle/EPDM interface, and 4) failure at a talc/talc interface. 

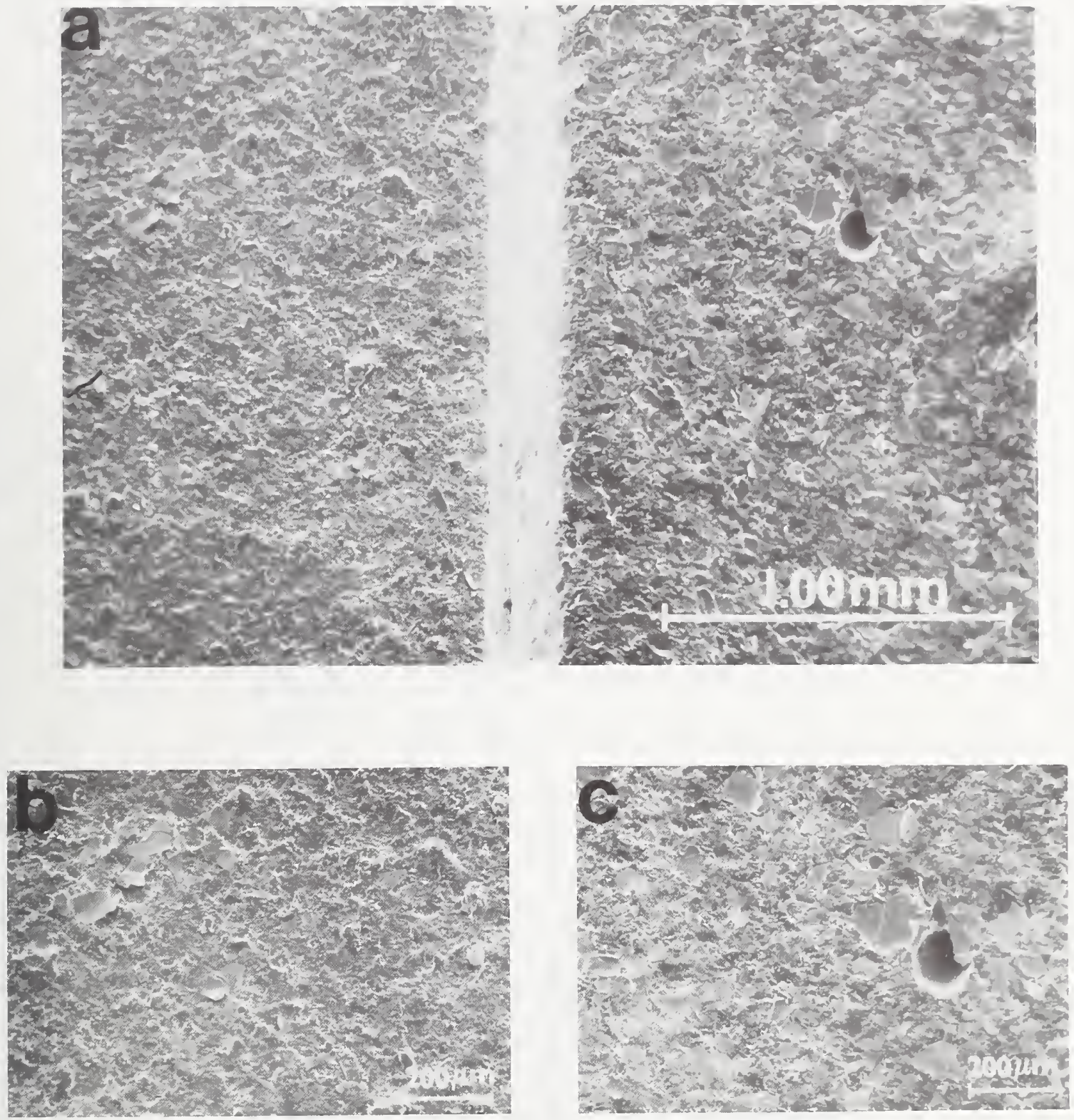

Figure 9. SEM micrographs of a failed peel joint cured for $1300 \mathrm{~h}$ which was made from a strip which was contaminated to a greyscale of 90. In Micrograph A, the two strips of the joint were "bookmatched" and imaged at $40 \mathrm{x}$ (the clean strip is on the right-hand side). In Micrographs $B$ (the clean strip) and $C$ (the contaminated strip), the disjoined surfaces were imaged at 100x. Note that most of the talc-like particles are on the clean side. 

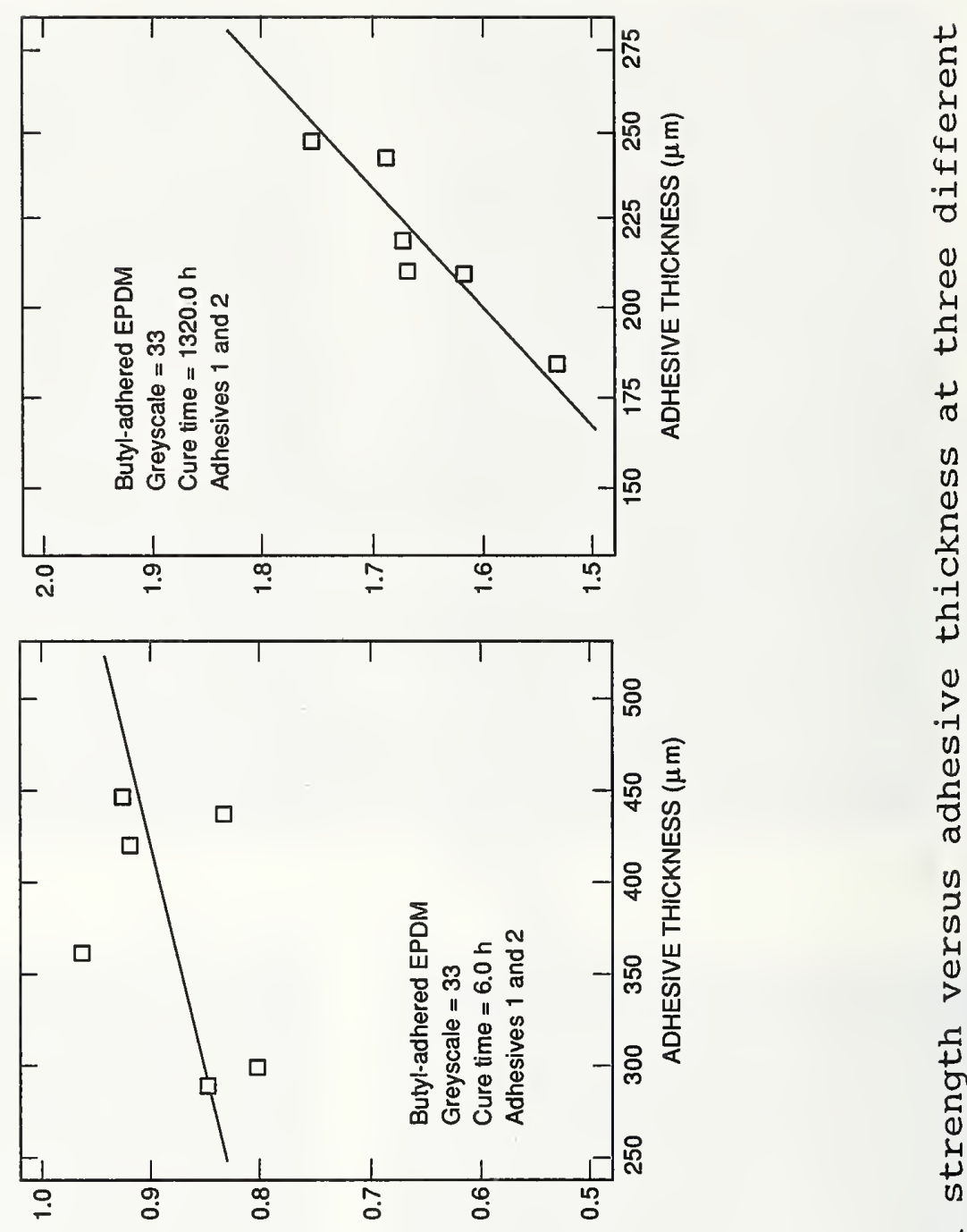

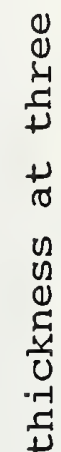
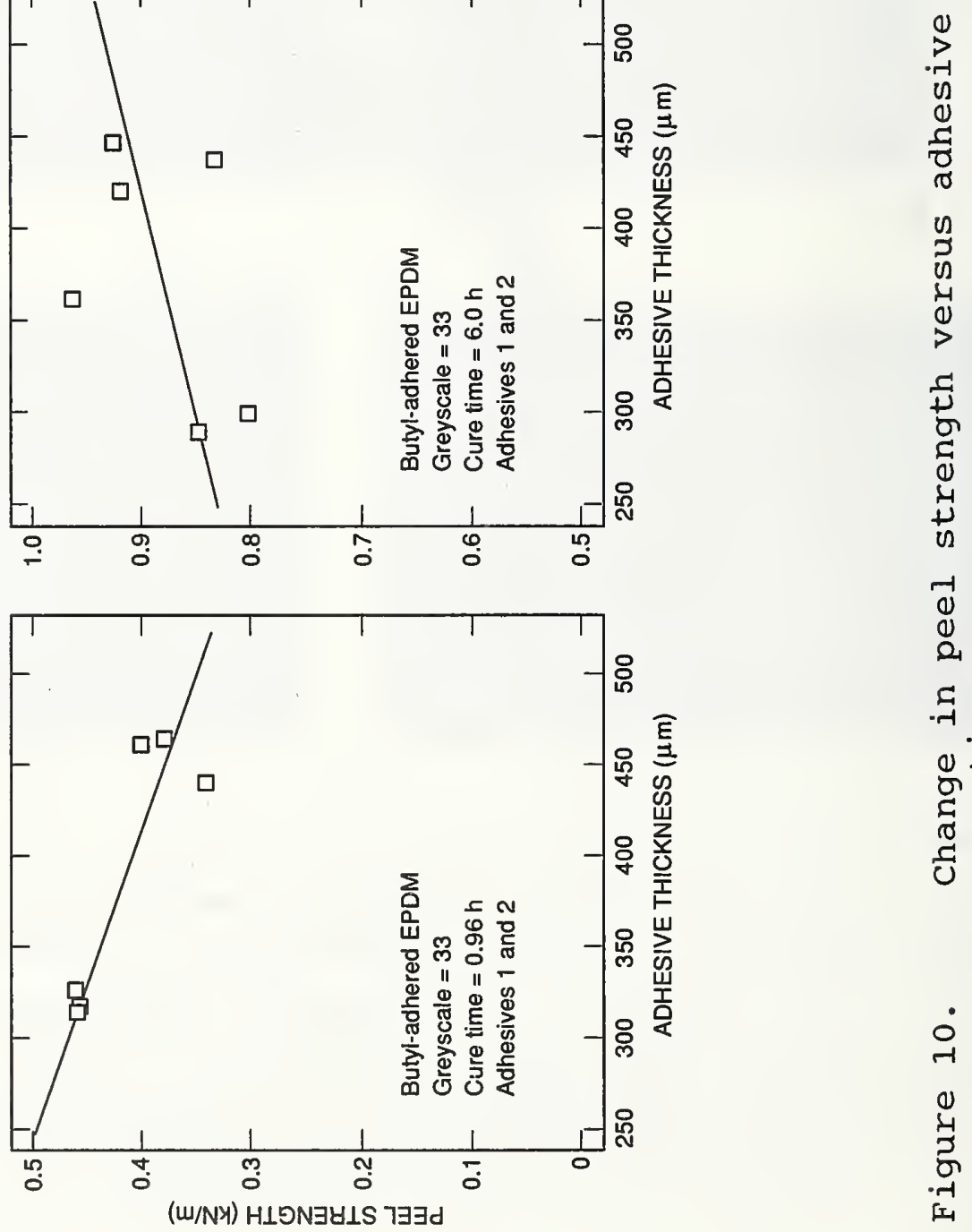

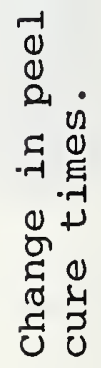




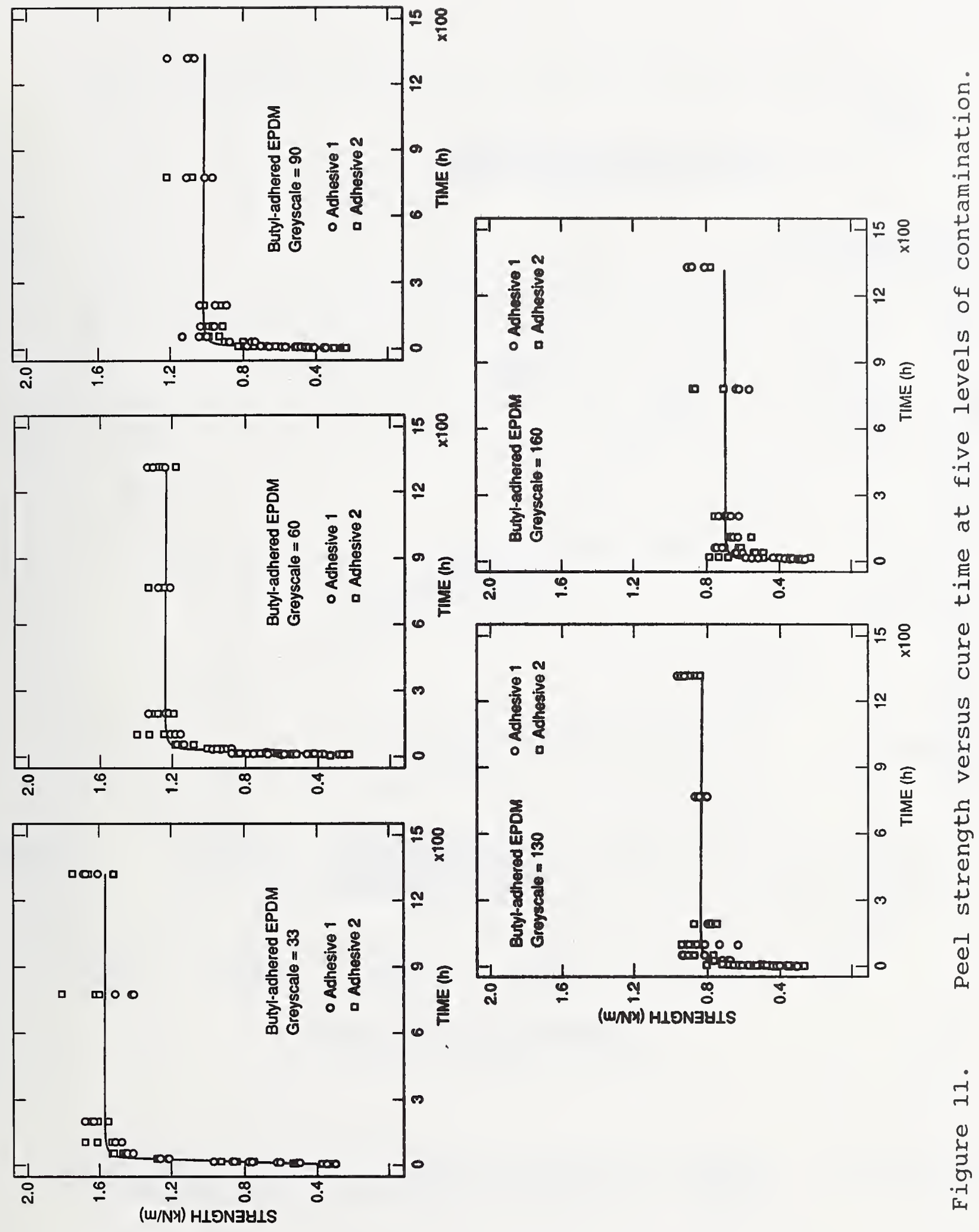




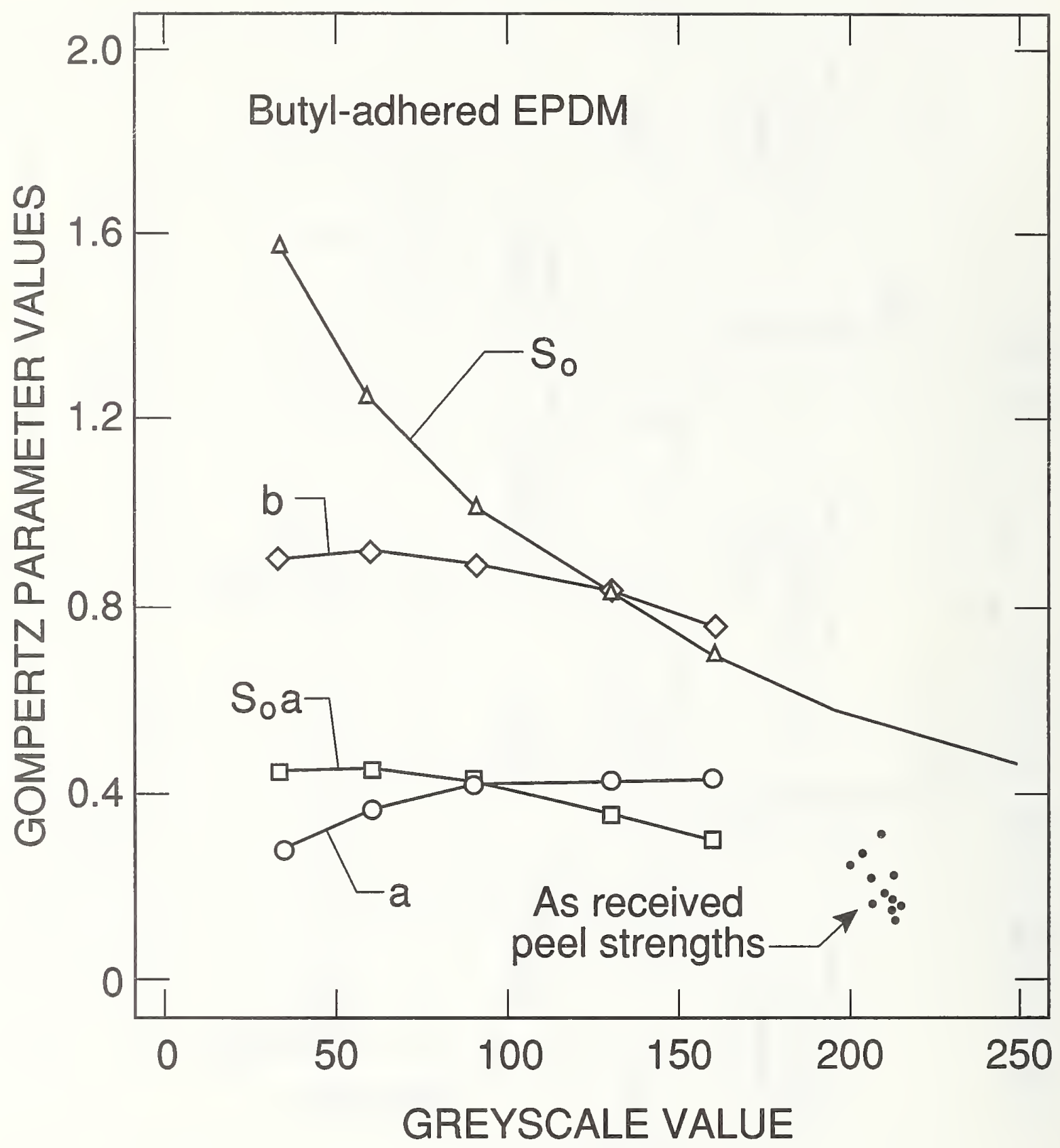

Figure 12. Gompertz parameter estimates versus contamination level. Parameters $\mathrm{a}$ and $\mathrm{b}$ are dimensionless. 


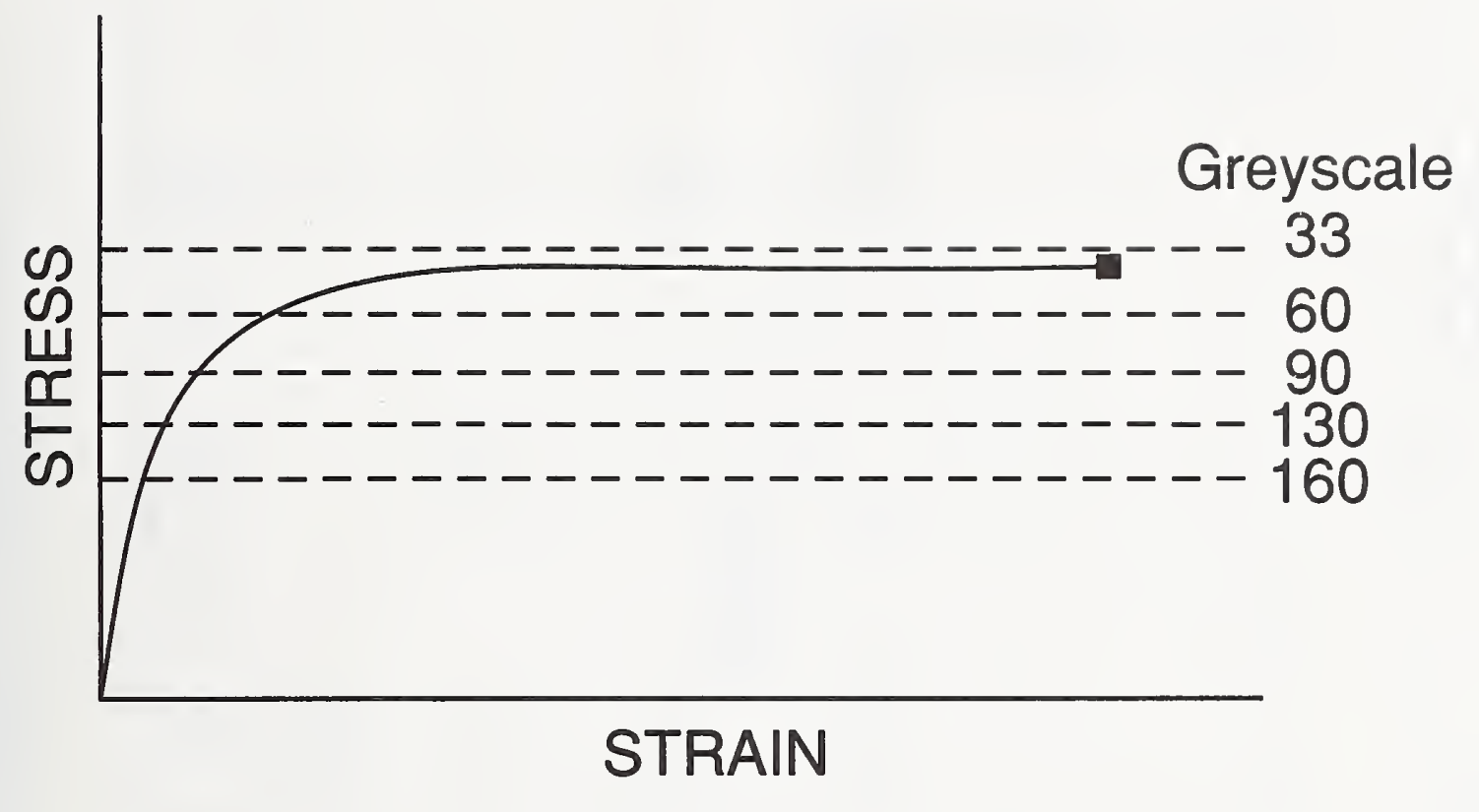

Figure 13. Schematic representation of the effect of contamination on peel strength when the peel rate is kept constant. 


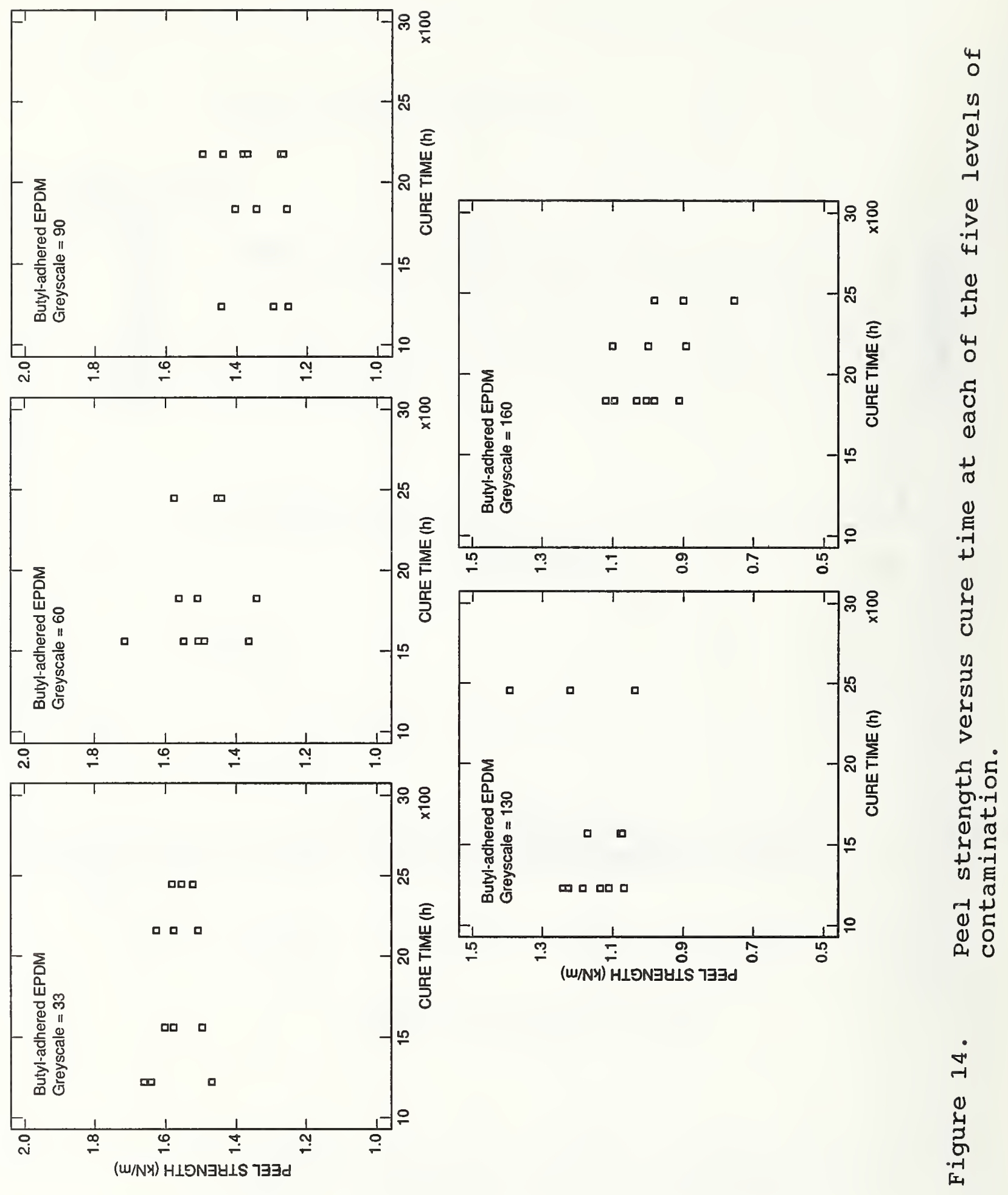




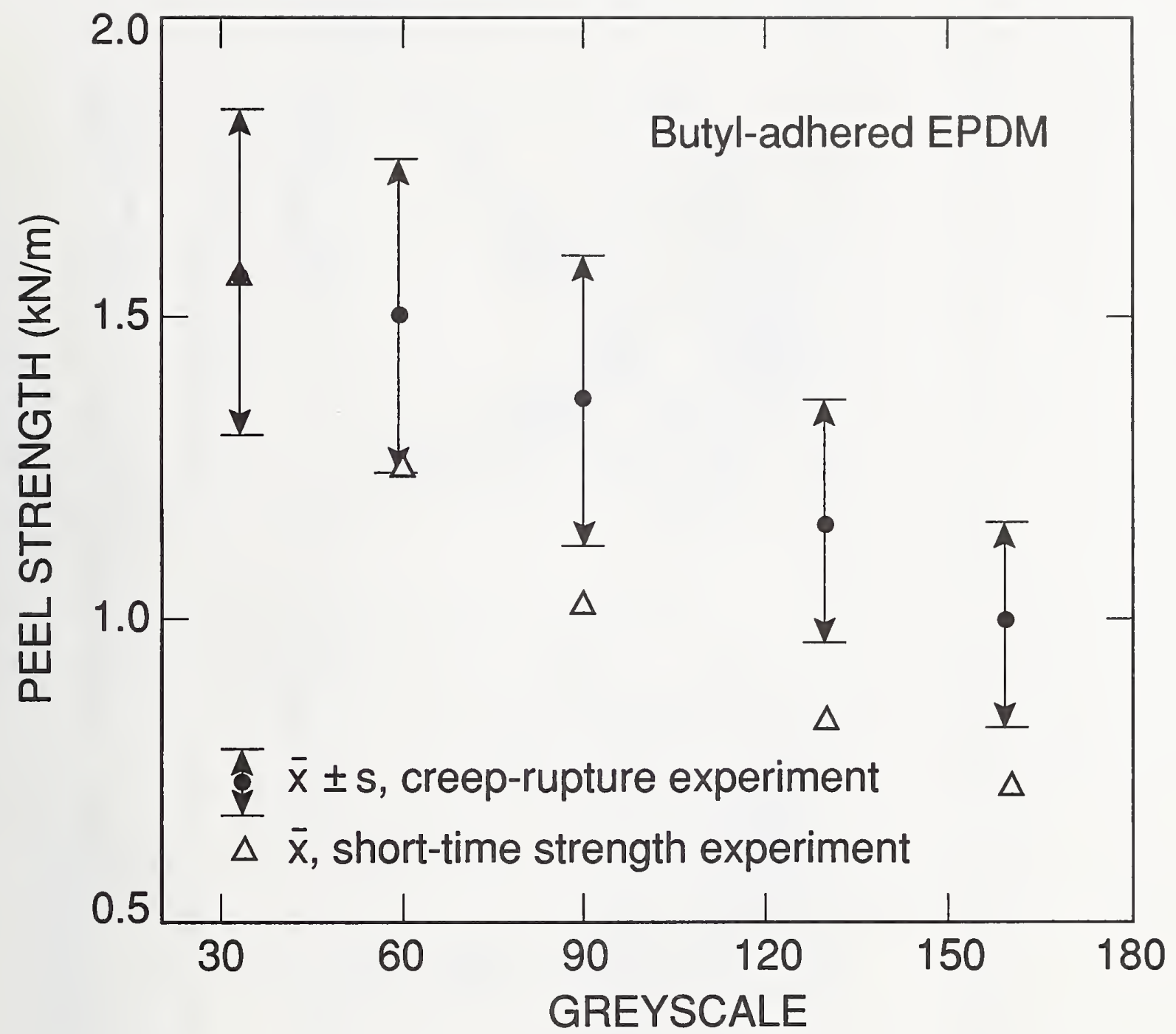

Figure 15. Peel strength versus greyscale level for the creep-rupture and short time strength joints. 


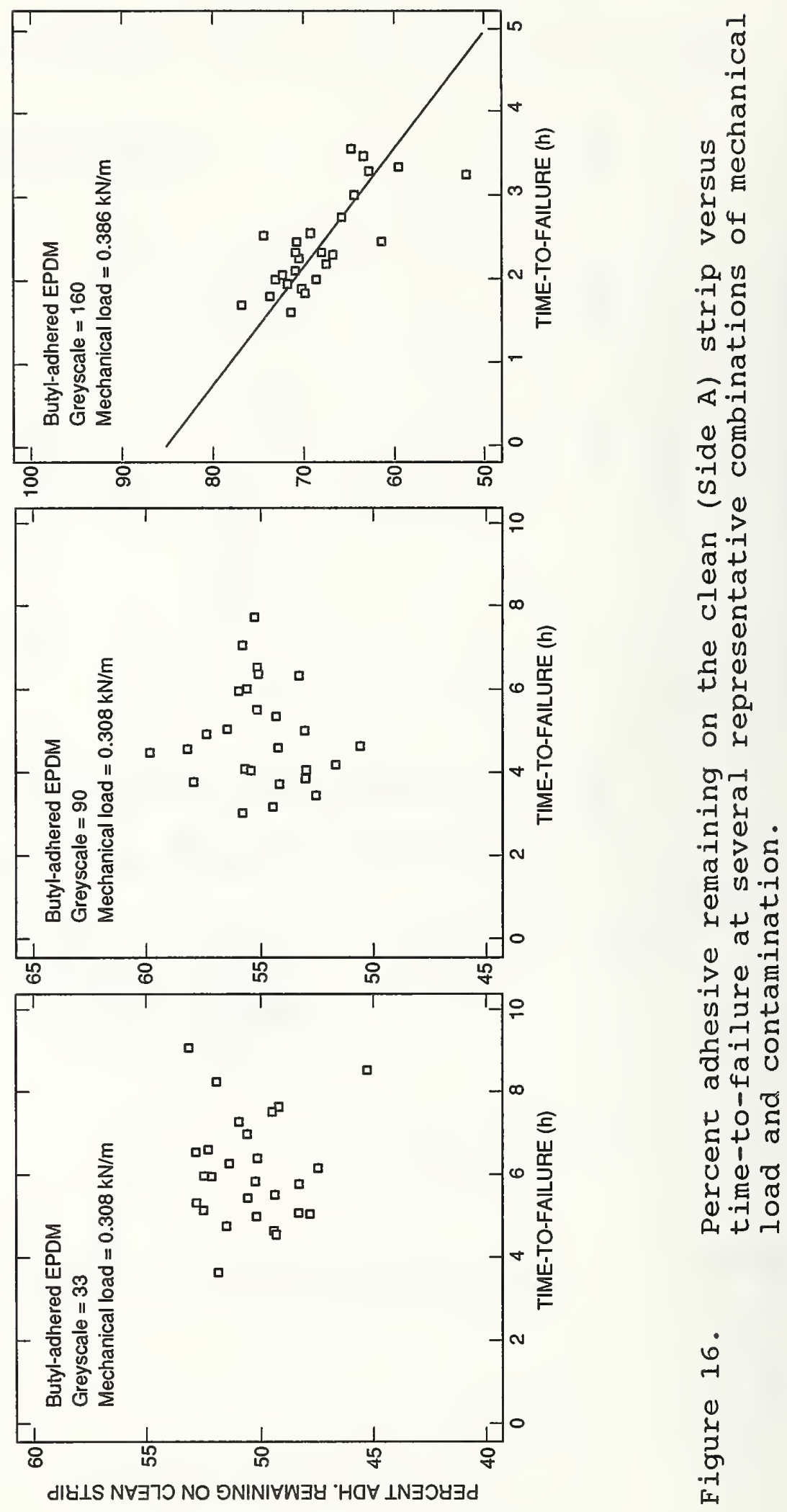



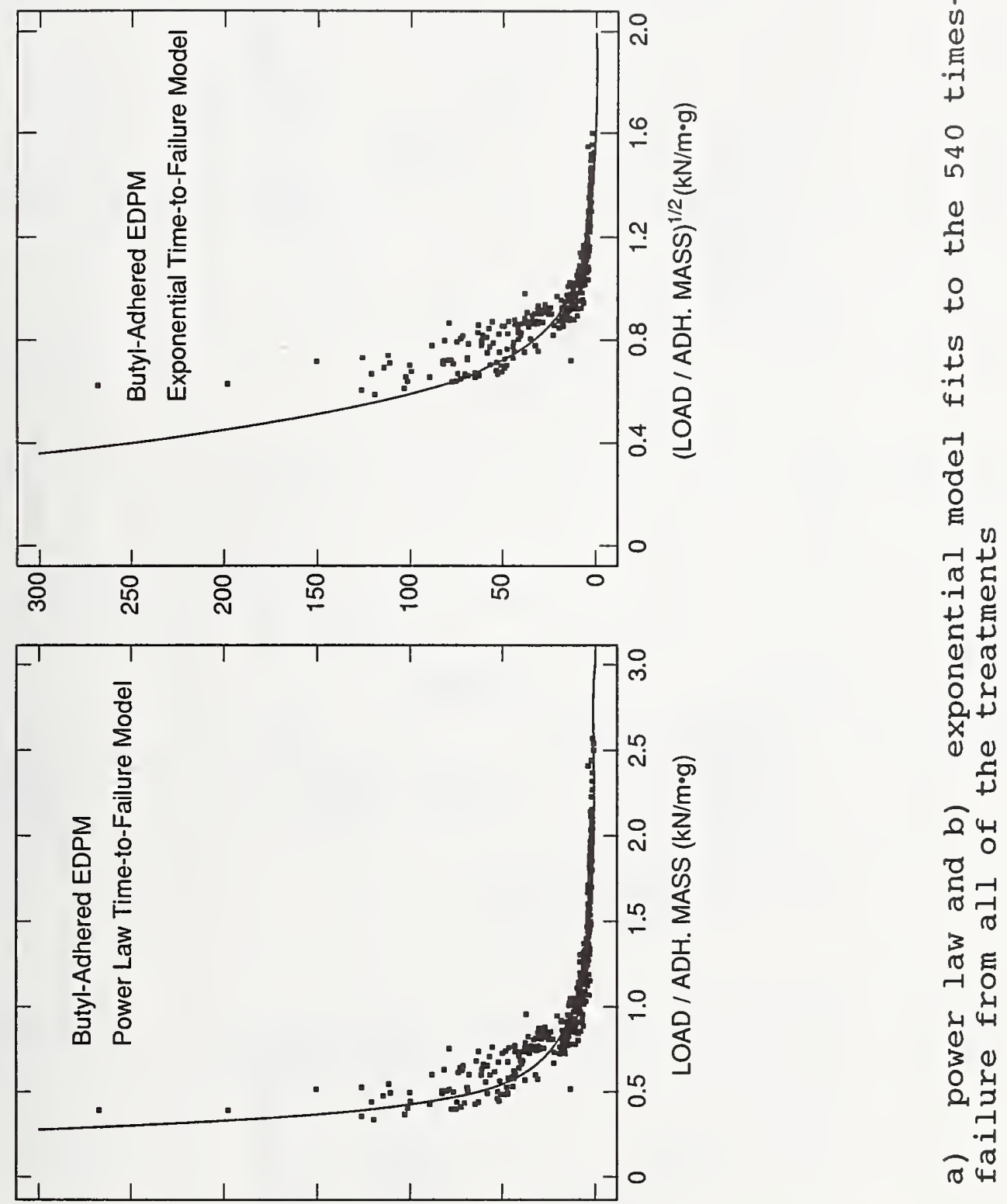


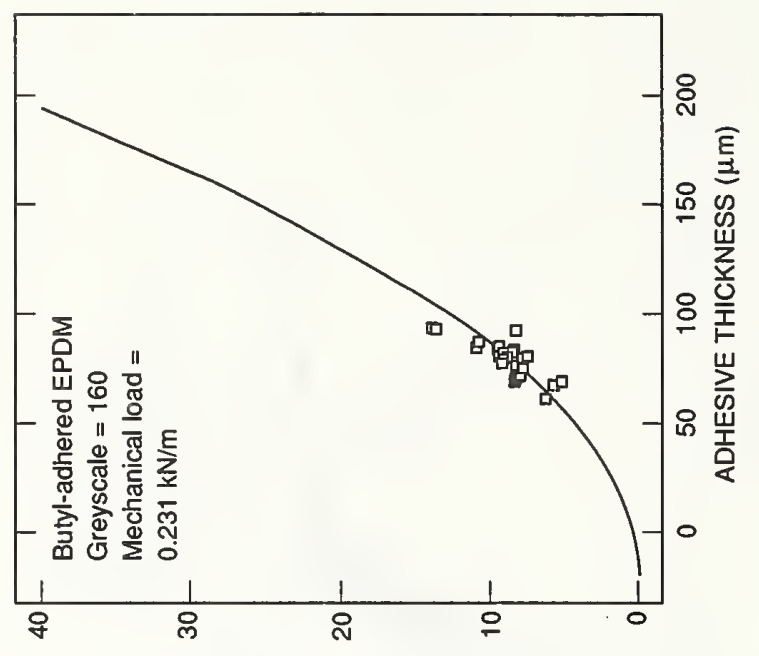

(4) $\exists$ ชกกาI $\forall \unlhd-O \perp-\exists W I \perp$

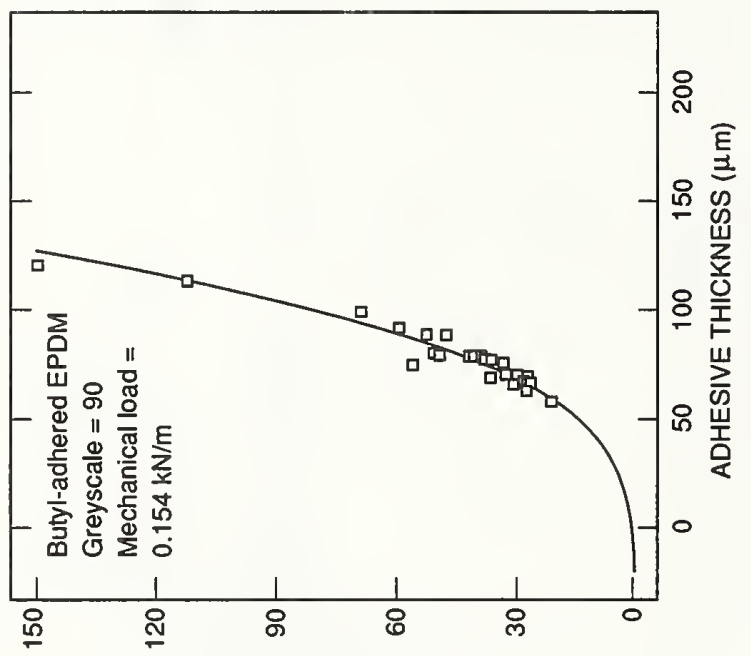

(4) $\exists y ก 7 \mid \forall J-O \perp-\exists W I \perp$
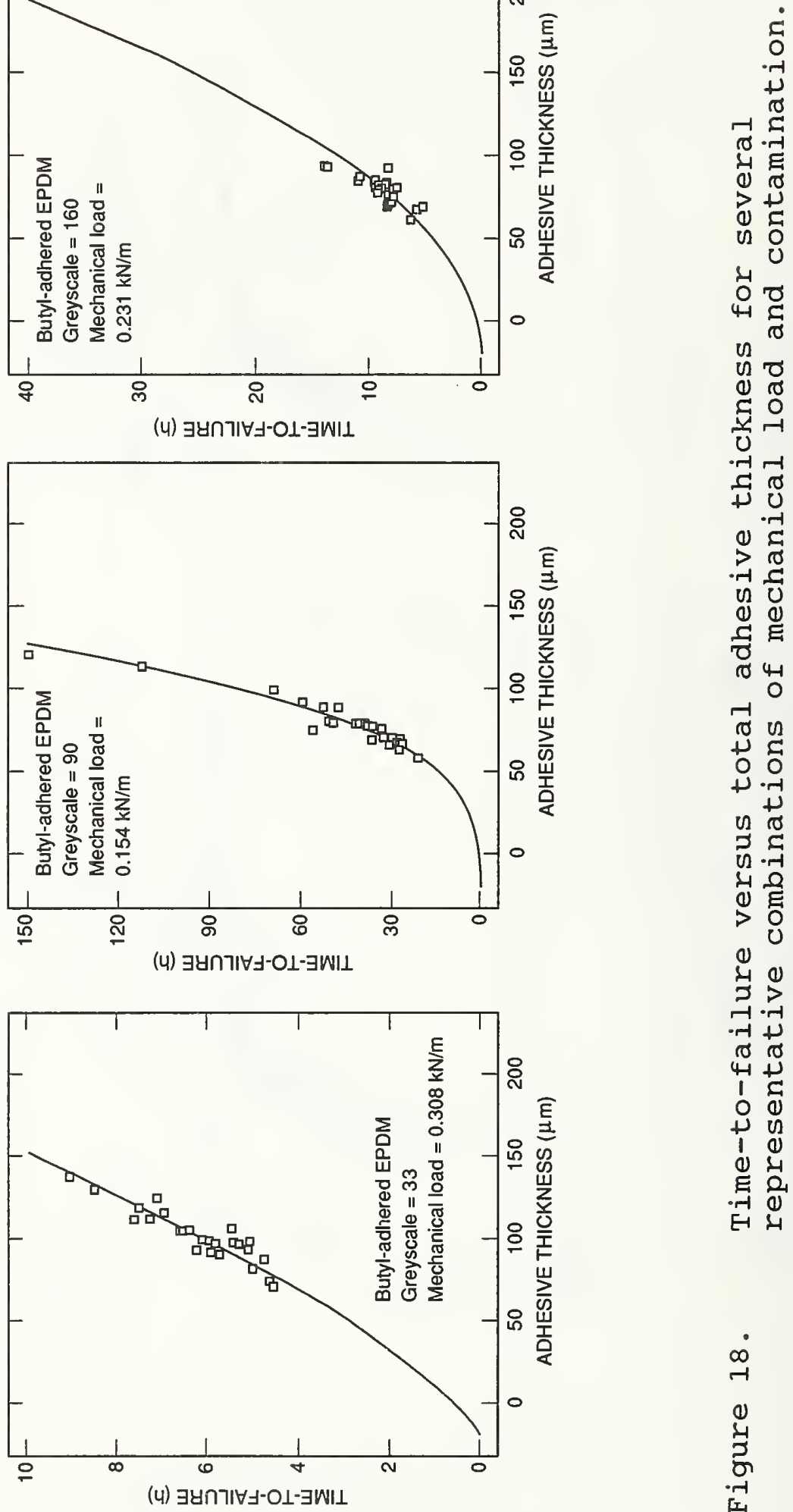


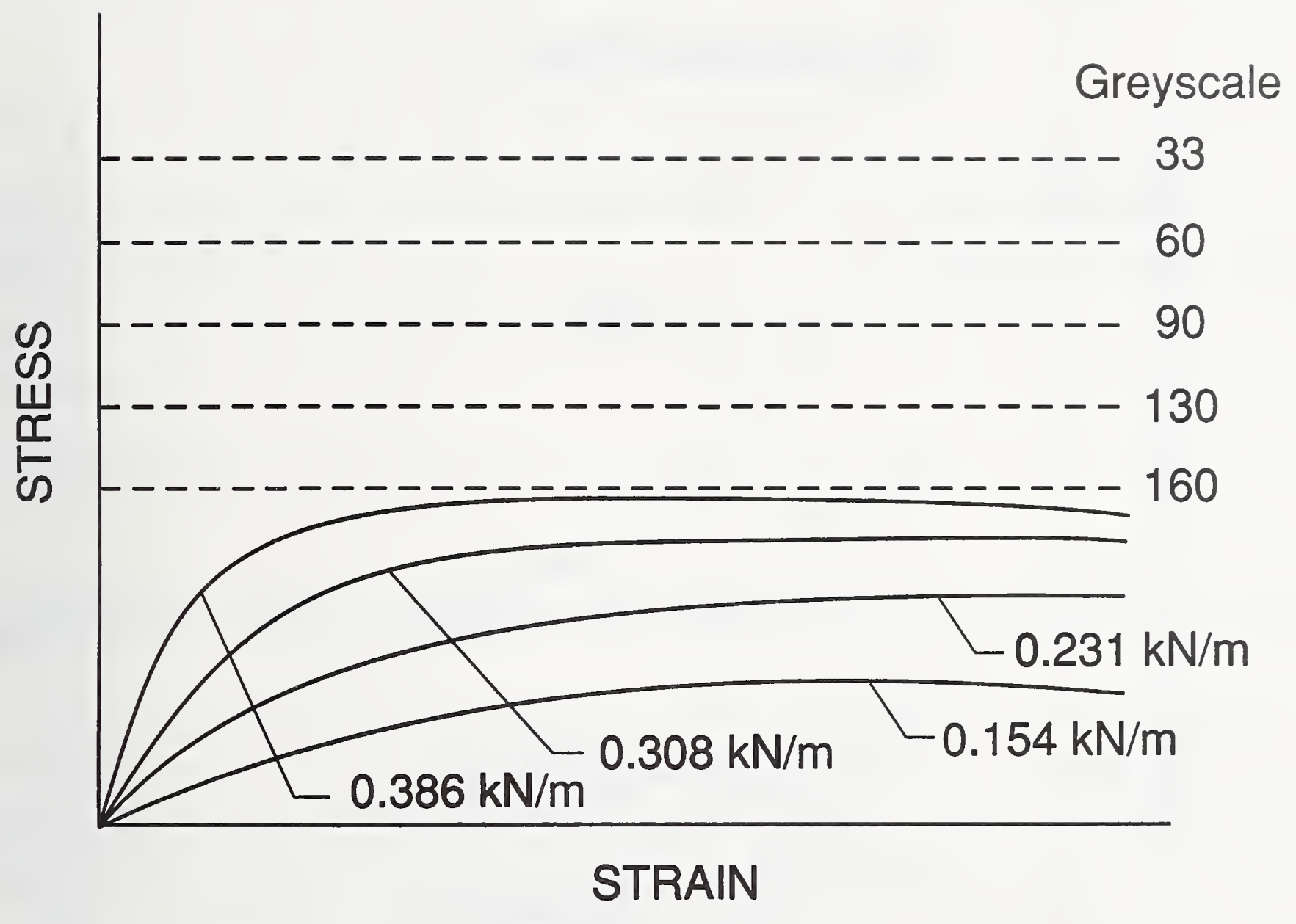

Figure 19. Schematic representation of the creep-rupture experimental results. 


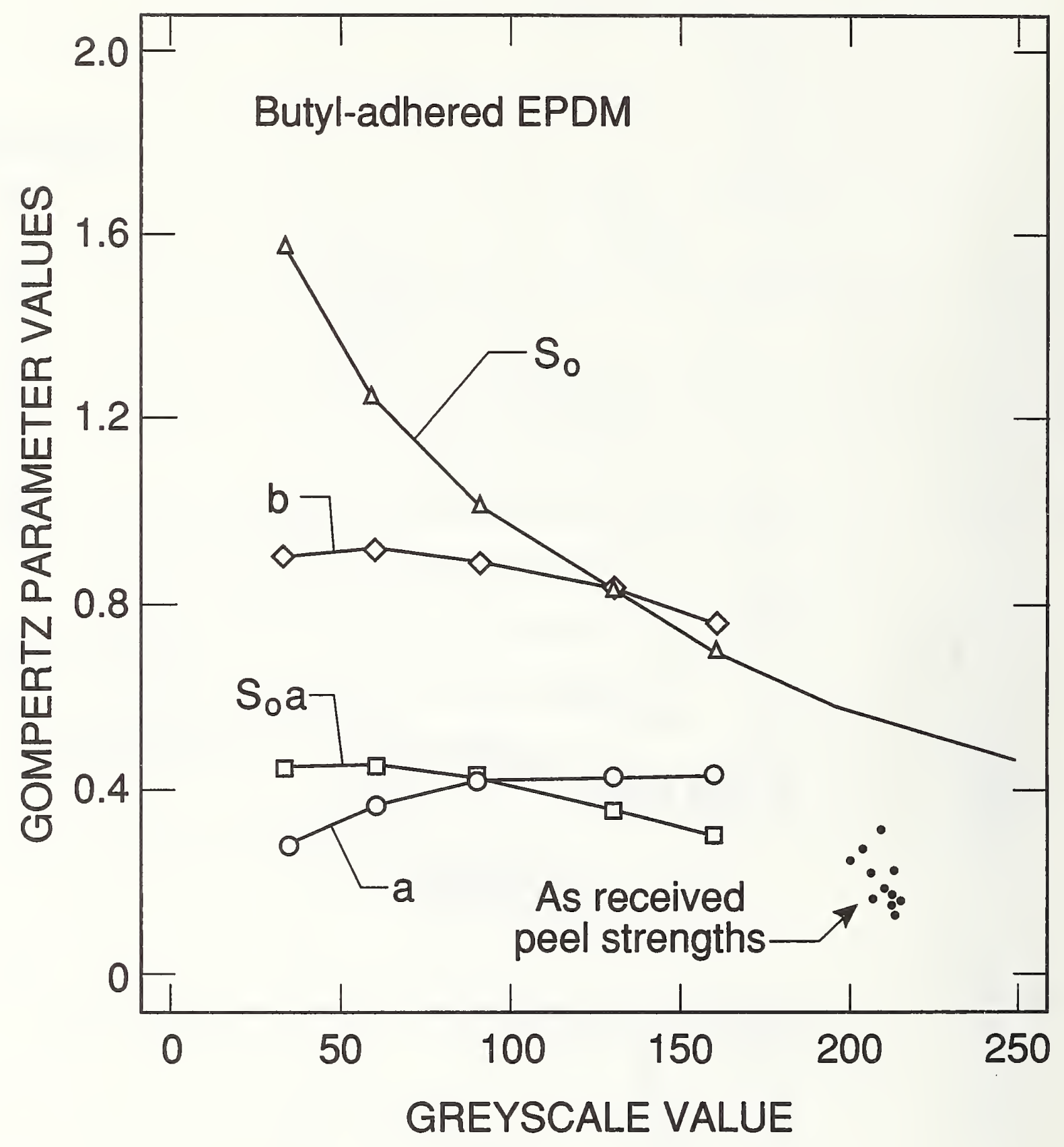

Figure 20.

Time-to-failure versus stress or load ratio for several viscoelastic materials. 
NIST-114A

(REV. 3-89)
U.S. DEPARTMENT OF COMMERCE NATIONAL INSTITUTE OF STANDARDS AND TECHNOLOGY

BIBLIOGRAPHIC DATA SHEET

1. PUBUCATION OR REPOAT NUMBER
NIST/BSS- 169
2. PERFORMING ORGANIZATION REPORT NUMBER
3. PUBUCATION DATE
MaY 1990

1. PUBUCATION OR REPOAT NUMBER

\begin{tabular}{|l}
\hline 2. \\
PERFORMING ORGA \\
3. \\
$\begin{array}{l}\text { PUBLCATION DATE } \\
\text { MaY } 1990\end{array}$
\end{tabular}

4. TITLE AND SUBTITLE

Strength and Creep-Rupture Properties of Adhesive-Bonded EPDM Joints Stressed in Peel

5. AUTHOR(S)

Jonathan W. Martin, Edward Embree, Paul E. Stutzman, and James A. Lechner

6. PERFORMING ORGANIZATION (IF JOINT OR OTHER THAN NIST, SEE INSTRUCTIONS)

U.S. DEPARTMENT OF COMMERCE

MATIONAL INSTITUTE OF STANDARDS AND TECHNOLOGY

GAITHERSBURG, MD 20899

7. CONTRACT/ORANT MUMBER

8. TYPE OF AEPORT AND PERIOD COVERED Final

9. SPONSORING ORGANIZATION NAME AND COMPLETE ADDRESS (STREET, CITY, STATE, ZIP)

Same as item \#6

10. SUPPLEMENTARY NOTES

DOCUMENT DESCRIBES A COMPUTER PROGRAM; SF-185, FIPS SOFTWARE SUMMARY, IS ATTACHED.

11. ABSTRACT (A 200-WORD OR LESS FACTUAL SUMMARY OF MOST SIGMIFICANT IMFORMATION. IF DOCUMENT INCLUDES A SIGNIFICANT BIBUOGRAPHY OR UTERATURE SURVEY, MENTION IT HERE.)

The most frequently reported defect in ethylene-propylene-diene terpolymer (EPDM) single-ply roofing systems is in field-formed joints. The causes of these joint defects are largely unknown, but they tend to occur a short time after a roof is installed.

The objectives of this research were 1) to determine the importance of the following material and fabrication variables in causing joint failures: adhesive thickness, cure time, mechanical load, adhesive type and surface cleanness, 2) to rank these variables as they affect the creep-rupture life and strength of butyl-adhered EPDM joints, and 3 ) to determine the maximum peel stress which EPDM joints can sustain over their design life. From our results, cure time and level of cleanness of the EPDM membrane have the greatest effect on joint strength; while the thickness of the adhesive and the magnitude of the mechanical load have the greatest effect on a joint's creep-rupture time-to-failure. Thus, the rankings of variables in creep-rupture and short-time strength experiments were different and this difference should have important implications in standards writing and in establishing performance requirements for EPDM roofing joints.

Creep-rupture results were used in determining the maximum design stress that butyl and neoprene-adhered EPDM joints can sustain when loaded in peel. The maximum sustainable stress is only a small fraction (less than 5\%) of the short-time yield strength of a joint. Thus, efforts should be made to insure that the field-formed joints are only subjected to small peel loads.

12. KEYWORDS (6 TO 12 ENTRIES; ALPHABETICAL ORDER; CAPITALZE ONLY PROPER NAMES; AND SEPARATE KEY WORDS BY SEMICOLONS)

butyl adhesive; creep-rupture life; EPDM; neoprene; peel performance criteria; seam; single-ply roofing; strain rate; stress-ratio; time-to-failure$$
13 .
$$

13. AVAILABIUTY

UNLIMITED

FOR OFFICIAL DISTRIBUTION. DO NOT RELEASE TO NATIONAL TECHNICAL INFORMATION SERVICE (NTIS).

ORDER FROM SUPERINTENDENT OF DOCUMENTS, U.S. GOVERNMENT PRINTING OFFICE,

WASHINGTON, DC 20402.

ORDER FROM NATIONOL TECHIUCAL INFORMATION SERVICE (NTIS), SPRIHGFIELO VA 22161

14. NUMBER OF PRINTED PAGES

59 





\section{Technical Publications}

\section{Periodical}

Journal of Research of the National Institute of Standards and Technology-Reports NIST research and development in those disciplines of the physical and engineering sciences in which the Institute is active. These include physics, chemistry, engineering, mathematics, and computer sciences. Papers cover a broad range of subjects, with major emphasis on measurement methodology and the basic technology underlying standardization. Also included from time to time are survey articles on topics closely related to the Institute's technical and scientific programs. Issued six times a year.

\section{Nonperiodicals}

Monographs-Major contributions to the technical literature on various subjects related to the Institute's scientific and technical activities.

Handbooks-Recommended codes of engineering and industrial practice (including safety codes) developed in cooperation with interested industries, professional organizations, and regulatory bodies.

Special Publications-Include proceedings of conferences sponsored by NIST, NIST annual reports, and other special publications appropriate to this grouping such as wall charts, pocket cards, and bibliographies.

Applied Mathematics Series-Mathematical tables, manuals, and studies of special interest to physicists, engineers, chemists, biologists, mathematicians, computer programmers, and others engaged in scientific and technical work.

National Standard Reference Data Series-Provides quantitative data on the physical and chemical properties of materials, compiled from the world's literature and critically evaluated. Developed under a worldwide program coordinated by NIST under the authority of the National Standard Data Act (Public Law 90-396). NOTE: The Journal of Physical and Chemical Reference Data (JPCRD) is published quarterly for NIST by the American Chemical Society (ACS) and the American Institute of Physics (AIP). Subscriptions, reprints, and supplements are available from ACS, 1155 Sixteenth St., NW., Washington, DC 20056.

Building Science Series-Disseminates technical information developed at the Institute on building materials, components, systems, and whole structures. The series presents research results, test methods, and performance criteria related to the structural and environmental functions and the durability and safety characteristics of building elements and systems.

Technical Notes-Studies or reports which are complete in themselves but restrictive in their treatment of a subject. Analogous to monographs but not so comprehensive in scope or definitive in treatment of the subject area. Often serve as a vehicle for final reports of work performed at NIST under the sponsorship of other government agencies.

Voluntary Product Standards-Developed under procedures published by the Department of Commerce in Part 10, Title 15, of the Code of Federal Regulations. The standards establish nationally recognized requirements for products, and provide all concerned interests with a basis for common understanding of the characteristics of the products. NIST administers this program as a supplement to the activities of the private sector standardizing organizations.

Consumer Information Series-Practical information, based on NIST research and experience, covering areas of interest to the consumer. Easily understandable language and illustrations provide useful background knowledge for shopping in today's technological marketplace.

Order the above NIST publications from: Superintendent of Documents, Government Printing Office, Washington, DC 20402.

Order the following NIST publications-FIPS and NISTIRs-from the National Technical Information Service, Springfield, VA 22161.

Federal Information Processing Standards Publications (FIPS PUB)-Publications in this series collectively constitute the Federal Information Processing Standards Register. The Register serves as the official source of information in the Federal Government regarding standards issued by NIST pursuant to the Federal Property and Administrative Services Act of 1949 as amended, Public Law 89-306 (79 Stat. 1127), and as implemented by Executive Order 11717 (38 FR 12315, dated May 11, 1973) and Part 6 of Title 15 CFR (Code of Federal Regulations).

NIST Interagency Reports (NISTIR) - A special series of interim or final reports on work performed by NIST for outside sponsors (both government and non-government). In general, initial distribution is handled by the sponsor; public distribution is by the National Technical Information Service, Springfield, VA 22161, in paper copy or microfiche form. 
U.S. Department of Commerce

National Institute of Standards and Technology

(formerly National Bureau of Standards)

Gaithersburg, MD 20899

Official Business

Penalty for Private Use $\$ 300$ 